\title{
Duality in Diversity: Cultural Heterogeneity, Language, and Firm Performance *
}

\author{
Matthew Corritore $^{1}$, Amir Goldberg ${ }^{1}$, and Sameer B. Srivastava ${ }^{2}$ \\ ${ }^{1}$ Stanford Graduate School of Business \\ ${ }^{2}$ Haas School of Business, University of California, Berkeley \\ WORKING PAPER \\ March, 2018
}

\begin{abstract}
How does cultural heterogeneity in an organization relate to its underlying capacity for execution and innovation? Existing literature often understands cultural diversity as presenting a tradeoff between task coordination and creative problem-solving. This work assumes that diversity arises primarily through cultural differences between individuals. In contrast, we propose that diversity can also exist within persons such that cultural heterogeneity can be unpacked into two distinct forms: interpersonal and intrapersonal. We argue that the former tends to undermine coordination and portends worsening firm profitability, while the latter facilitates creativity and supports greater patenting success and more positive market valuations. To evaluate these propositions, we use unsupervised learning to identify cultural content in employee reviews of nearly 500 publicly traded firms on a leading company review website and then develop novel, time-varying measures of cultural heterogeneity. Our empirical results lend support for our two core propositions, demonstrating that a diversity of cultural beliefs in an organization does not necessarily impose a trade-off between operational efficiency and creativity.
\end{abstract}

${ }^{*}$ We thank Glassdoor for providing the employee review data and Lee Fleming for sharing the patent data that we used in this study. We also thank seminar participants at University of Illinois School of Labor and Employment Relations; University of Chicago, Booth School of Business; IESE Business School; Kellogg School of Management, Northwestern University; Arison School of Business at IDC Herzliya, Israel; and participants at the Lugano Organizations Conference, the Stanford/Berkeley Organizational Behavior Student Conference, the Consortium on Competitiveness and Cooperation Conference for Doctoral Student Research at the Wharton School, University of Pennsylvania, the Carnegie School of Organizational Learning Conference, and the International Conference on Computational Social Science. We are also grateful to Lara Yang for the research support she provided. The usual disclaimer applies. 
Whether deliberatively cultivated or naturally arising, every organization develops a culture - a system of meanings and norms shared by its members. An organization's culture can influence the success of its members and the organization as a whole through its effects on individual motivation and commitment, interpersonal coordination, and group creativity and innovation (Chatman and O'Reilly, 2016). Although organizational scholars often ask how the content or intensity of culture relates to performance - for example, how shared beliefs and norms about the importance of crossfunctional collaboration can boost or diminish firm profitability - a growing literature has focused instead on the consequences of cultural heterogeneity for organizational productivity and vitality. Research in this vein asks: When is a diversity of ideas and beliefs conducive to organizational success and when is it instead detrimental?

Different literatures have provided varied and inconsistent answers to this question. One line of work sees cultural heterogeneity as an obstacle to firm performance. Research on cultural strength, for example, emphasizes the importance of cultural agreement among organizational members. This perspective argues that incompatibilities in employees' beliefs and normative expectations can impede their ability to coordinate tasks (Denison and Mishra, 1995; Weber and Camerer, 2003; Kotter and Heskett, 1992), thereby producing a negative relationship between cultural heterogeneity and firm performance. In contrast, research by economic and cultural sociologists typically views cultural diversity as an advantage. This perspective conceptualizes heterogeneity as a reflection of the cultural "toolkit" available to individuals (Swidler, 1986). When organizational members have access to a broad array of cultural resources, the organization is assumed to have greater capacity for creativity and innovation to address changing, uncertain, and competing environmental demands (Stark, 2011; Hallett and Ventresca, 2006).

This tension is also manifest in work on demographic diversity. Although it has primarily focused on diversity in ascribed characteristics such as sex or age and in functional experiences, this literature has also called attention to deep-level differences in how people think and what they believe about group and organizational culture (Harrison et al., 1998). Whereas some studies 
highlight demographic diversity's negative implications for performance through the facilitation of conflict and coordination inefficiencies, others focus on its positive effects on collective learning and creativity (Fiol, 1994; Van Knippenberg and Schippers, 2007; Page, 2007; Lau and Murnighan, 1998).

Taken together, these literatures suggest that cultural heterogeneity presents a fundamental trade-off: Culturally diverse firms are better at creative problem-solving, but this capability comes at the cost of decreased coordination and efficiency. Empirical support for such a trade-off, however, remains meager and unsettled. We reconcile these divergent theoretical perspectives and mixed empirical findings by drawing on the core insight that cultural heterogeneity is not a unidimensional construct. Existing literature has conceptualized this diversity exclusively through the prism of differences between individuals. Yet heterogeneity can also exist within persons (Bunderson and Sutcliffe, 2002; Goldberg et al., 2016; Morris et al., 2015). Building on this insight, we propose that there are two distinct forms of cultural heterogeneity in organizations: that stemming from misalignment among members' cultural perceptions of the organization and that arising from the breadth of the cultural resources that individuals use to understand and make sense of the organization.

As illustration, imagine a stylized world in which there exist only two possible beliefs, $A$ and $B$, about how work gets done or should get done. Imagine further two hypothetical organizations. In the first, half of the employees espouse belief $A$ and the other half espouse belief $B$. In the second, all employees espouse both beliefs. The two organizations appear similarly culturally heterogeneous in that the two beliefs are equally prevalent. Yet the nature of this diversity varies between the two. In the former, heterogeneity stems from divergent cultural beliefs between people. We refer to this as interpersonal heterogeneity. The second organization is characterized by intrapersonal heterogeneity: individuals have a multiplicity of cultural beliefs about the organization. Although interpersonal and intrapersonal heterogeneity are interrelated, they are analytically distinct.

Integrating insights from demographic diversity, group learning, and cultural sociology, we 
argue that interpersonal and intrapersonal heterogeneity are related to different organizational outcomes. Consistent with work on the organizational consequences of cultural strength (e.g., Kotter and Heskett, 1992), we theorize that interpersonal heterogeneity will be linked to a firm's coordination and execution capabilities and thus to indicators of performance such as profitability. In contrast, drawing on group learning research (e.g., Page, 2007) and the toolkit theory of culture (e.g., Swidler, 1986), we posit that intrapersonal heterogeneity will be tied to a firm's capacity for creative exploration and therefore to patenting success and market expectations of future growth. Decomposing cultural heterogeneity into its interpersonal and intrapersonal components reveals that there need not be a trade-off between organizational coordination and innovation-for example, a culture with low interpersonal but high intrapersonal heterogeneity can facilitate coordination without necessarily undermining creative problem-solving and innovation.

Empirically, the methods most commonly used to study organizational culture - chiefly selfreports (O'Reilly et al., 1991) and participant-observation (Kunda, 2009; Turco, 2016) — can yield rich insight but are not well-suited to generating dynamic measures of cultural heterogeneity for a large, diverse sample of firms. In part for this reason, prior work examining the link between culture and firm performance has tended to rely on cross-sectional designs and side-stepped questions about the dynamic interplay between the two. Moreover, survey-based methods highlight variation between respondents (O'Reilly et al., 1991) but are less well-suited to detecting differences in intrapersonal heterogeneity across organizations.

To overcome these limitations, we apply the tools of computational linguistics to derive novel, time-varying measures of interpersonal and intrapersonal heterogeneity for a sample of nearly 500 publicly traded companies on Glassdoor (www.glassdoor.com) - a career intelligence website that allows employees to evaluate and write reviews about their firms. Given that cultural content can appear in a wide variety of reviews, we use unsupervised learning to identify distinct cultural topics in the nearly one million sentences that contain the word "culture" and its synonyms. We then train a topic model, which we fit to all employee reviews in our sample, and derive our 
cultural measures based on these identified topics. To move closer to causal estimates of the relationship between these two forms of cultural heterogeneity and firm performance, we apply coarsened exact matching (Iacus et al., 2012) to identify pairs of firms that vary on the cultural dimensions of interest but are otherwise observationally equivalent. Our results demonstrate that, counter to prevailing wisdom, cultural heterogeneity does not necessarily embody a conflict between execution efficiencies and creative capacity in organizations. Moreover, our study provides the first evidence, to our knowledge, of a dynamic relationship between cultural heterogeneity and different performance outcomes in a comprehensive, longitudinal dataset of the largest firms in the U.S.

\section{Cultural Heterogeneity and Organizational Performance}

\section{Why Cultural Heterogeneity Matters}

Culture is often understood by organizational scholars as a "system of publicly and collectively accepted meanings" (Pettigrew, 1979, p. 574) that a group -including a formal organizationdevelops in response to challenges of external adaptation and internal integration. These meanings manifest both in the form of deeply rooted assumptions and beliefs about the world, as well as in the normative and behavioral expectations that these beliefs and assumptions prescribe (Schein, 2010).

What aspects of culture matter for organizational success? Organizational culture has been characterized along multiple dimensions - for example, content, or which specific beliefs and behavioral norms are prevalent; and intensity, or the degree to which members are willing to sanction non-conforming and reward normatively compliant behavior - that have varying implications for firm performance (Chatman and O'Reilly, 2016). The content of cultural values, beliefs, and norms is important because it influences how people work to accomplish tasks within firms. For example,

early in the company's development, Facebook employees purportedly subscribed to the value of "move fast and break things," which influenced their behavior by prompting them to prioritize 
speed, autonomy, and tolerance of mistakes over other considerations. Although we acknowledge that the content of such norms and the intensity with which they are reinforced can have important consequences, our investigation focuses instead on a different cultural feature: heterogeneity, or the variety and distribution of ideas, beliefs, and normative expectations held by organizational mem-

bers. Returning to the Facebook example, a cultural heterogeneity perspective would focus less on specific values such as "move fast and break things" and more on the variety and distribution of all prevailing ideas and beliefs that guide work within Facebook.

Our focus on heterogeneity is consistent with the distributive approach to analyzing organizational culture (Harrison and Carroll, 2006). This perspective acknowledges that culture's role in organizational success is often idiosyncratic such that the cultural content associated with success varies by industry and a firm's choice of competitive strategy. Moving fast may be conducive to success for an organization competing in a fast-paced and undetermined market such as the one Facebook tried to conquer during its early years but not, for example, for a hospital in which minor errors can have devastating implications. In many cases, focusing on the distribution of cultural orientations in an organization can be more informative about firm performance - and generalize to organizations in other competitive contexts - than investigations into the specific beliefs and norms that give rise to those performance outcomes. In other words, consistent with previous work that focuses on the distribution of culture, we propose that cultural heterogeneity has implications for firm performance that are independent of cultural content and intensity.

\section{Heterogeneous Perspectives on Cultural Heterogeneity}

Organizational theorists who study cultural heterogeneity see it as both a blessing and as a curse. Although work on organizational culture is vast and fragmented (Chatman and O'Reilly, 2016), two conflicting themes on the relationship between cultural heterogeneity and performance prevail. The first, most strongly associated with research on cultural strength, sees cultural heterogeneity as an impediment to organizational performance. This line of work conceptualizes culture as a 
solution to a complex coordination problem. Heterogeneous cultures, it is argued, are detrimental to organizational performance because they undermine interpersonal integration and erode internal cohesion.

Two specific mechanisms undergird the theorized link between cultural strength and organizational performance. First, cultural homogeneity is assumed to promote interpersonal coordination by facilitating goal alignment and behavioral consistency (Kreps, 1996; Gordon and DiTomaso, 1992; Weber and Camerer, 2003). A lack of such alignment can produce coordination failures. For example, an employee working in accordance with a norm that encourages speed, autonomy, and a willingness to make mistakes will coordinate less well with another employee behaving in accordance with a norm emphasizing deliberateness, caution, and precision. Second, the absence of a unified and shared culture can generate fragmentation and a sense of personal estrangement. This can lead to conflict, as well as a decline in morale and a dampening of individual commitment and motivation (Martin, 1992; Jehn et al., 1999).

In contrast, the benefits of cultural heterogeneity for organizational performance become apparent when culture is conceptualized as a set of cognitive resources that members deploy in adapting to external changes and competitive pressures. This perspective sees cultural heterogeneity as an advantage rather than an obstacle. Core to this view is the assumption that creativity - the application of novel and useful solutions to problems (Amabile, 1996, 1988) - stems from the ability to recombine existing ideas in unconventional ways (Fleming, 2001; Uzzi et al., 2013; de Vaan et al., 2015). Drawing on these insights, researchers who emphasize the learning benefits of cultural diversity for performance argue that it does so by promoting a capacity for creative problem solving. This capacity derives not only from the fact that culturally diverse teams draw on a breadth of ideas and interpretative lenses but also from the superadditive effects of this breadth: the novelty that emerges when ideas intersect and recombine (Page, 2007; Tadmor et al., 2012b). The combination, for example, of a profit-oriented banking culture and a development-oriented social mission enabled the banks in Battilana and Dorado's (2010) study to pioneer commercial microfinance in Bolivia 
in the early 1990s.

Culturally heterogeneous organizations learn more effectively by fusing different schemas, scripts, and interpretive understandings to generate novel solutions. Cultural homogeneity, in contrast, can be detrimental to a firm's capacity for creativity for at least two reasons. First, employees in culturally uniform organizations are slower to recognize the need for change than their counterparts in organizations with diverse cultures (Lant and Mezias, 1992). Second, whereas cultural strength can foster first-order learning - for example, determining how to more efficiently execute tasks that are known to be important for marketplace success, it can inhibit second-order learning-identifying which new tasks to take on in response to a new or changing competitive landscape (Denison, 1984).

These competing perspectives on the relationship between cultural heterogeneity and performance are also echoed in research on relational demography. This line of work has mostly examined the consequences of differences in ascribed traits (such as sex, race, and age) and in backgrounds (such as functional experience, education and tenure) on group cohesion and performance (Tsui et al., 1992; Pfeffer, 1983). Research in this vein often assumes that differences at the surface level, such as race and age, also reflect disagreements at a deeper level of attitudes and beliefs. When these attitudes and beliefs relate to shared meanings, assumptions, and normative expectations, they become the cognitive material that makes up organizational culture. As Harrison et al. (1998) point out, demographic differences relate to attitudinal differences early in a group's life but tend to wane as members coordinate their cultural orientations over time. Demographic diversity, in other words, is not necessarily tantamount to cultural diversity. Nevertheless, work on the relationship between demographic diversity and performance is consistent with the literature on culture. On the one hand, demographic differences, especially when different dimensions of categorical dissimilarity reinforce one another, foster subgroup conflict and erode group cohesion and performance (Lau and Murnighan, 1998). At the same time, under certain conditions-such as functional interdependence - cultural heterogeneity can allow group members to bring together varying perspectives and ideas in ways that can enhance creativity and innovation (Jehn et al., 
1999; Van Knippenberg and Schippers, 2007).

\section{Interpersonal and Intrapersonal Cultural Heterogeneity}

Taken together, these literatures suggest that cultural heterogeneity presents a fundamental trade-off: Culturally diverse firms are better at creative problem-solving, but this capability comes at the cost of decreased coordination and efficiency. Yet empirical support for the existence of such a trade-off is scant and inconclusive. Sørensen (2002), for example, theorizes that the negative effects of cultural heterogeneity on firm performance will attenuate in volatile contexts, which ought to favor firms with a greater capacity for adaptation; however, he finds inconsistent support for this contention. Similarly, Kotrba et al. (2012) report that the relationship between cultural heterogeneity and firm performance is contingent on various other cultural attributes and varies by performance indicator (e.g., market-to-book ratio versus return on assets), while Burt et al. (2000) identify additional network-based market contingencies of strong cultures.

We argue that these mixed empirical findings in part reflect a theoretical shortcoming - the assumption that cultural heterogeneity is unidimensional and arises predominantly from dissimilarities between people. The positive effects of heterogeneity on creativity and problem-solving, for example, are often assumed to emerge from the combination of disparate beliefs that are otherwise distributed across individuals (Page, 2007). Similarly, prevailing organizational culture constructs tend to emphasize between-person differences. Cultural consensus, for example, refers to the degree of alignment between group members on which normative expectations matter (Chatman and O'Reilly, 2016).

Yet heterogeneity can also exist within individuals. For example, in team diversity research, Bunderson and Sutcliffe (2002) show that heterogeneity derives not only from differences between

people - the variety of functional experts on a team - but also within individuals - the aggregate functional breadth of team members. Extending this insight to the realm of organizational culture and drawing on the idea that culture is a toolkit of multiple and potentially inconsistent cognitive 
resources (Swidler, 1986), we propose that heterogeneity can arise in two conceptually distinct ways. The first is the familiar between-person route: it can surface from cultural misalignment between organizational members. The second is a heretofore unexamined within-person pathway: when organizational members subscribe to multiple and potentially incompatible beliefs and values.

Although within-person heterogeneity has been mostly overlooked by the literature on organizational culture, there is considerable evidence to support its existence. Firms commonly encourage their employees to adopt a broad and potentially inconsistent set of values. Take Netflix, the online DVD rental and streaming service, as an example. The company's influential 126 page-long culture statement includes value statements ranging from freedom and autonomy to curiosity and responsibility. ${ }^{1}$ Some of these values appear to be at odds with one another. For instance, Netflix emphasizes selflessness and teamwork but also a relentless pursuit of individual performance. The culture slidedeck states in one place that "We're a team, not a family...," but then goes on to issue the stern warning that, "...adequate performance gets a generous severance package."

Formal statements and espoused values are, of course, often aspirational and do not necessarily represent employees' lived experiences. No one in Enron, at least as far as we know, officially endorsed malfeasance. There are nevertheless reasons to expect that, like formal mission statements, enacted culture can also encompass a multiplicity of ideas, including ones that depart from official doctrine. Support for this view comes from two interrelated bodies of research. The first, hailing from cultural sociology, argues that people are cognitively equipped to internalize and selectively deploy multiple, coinciding cultural frames. This approach conceives of culture as a loosely-held repertoire or cultural "toolkit" (Swidler, 1986). Research in cognitive and cultural psychology generally supports this conceptualization. People often hold multiple and often inconsistent cognitive schemas (DiMaggio, 1997) and are capable of identifying with multiple cultural identities (Morris et al., 2015). Different situations invoke the deployment of different cultural lenses. Participants

\footnotetext{
${ }^{1}$ Downloaded more than 10 million times, the slide deck was hailed by Facebook's Chief Operating Officer, Sheryl Sandberg, as the "most important document ever to come out of the valley."
} 
in Swidler's (2001) study of romantic relationships, for example, at times described their bonds through a prism of love and selfless commitment and at others emphasized their relationships' rational and instrumental foundations. Individuals, in other words, do not necessarily subscribe to a single and internally coherent cultural order. Rather, they embody multiple cultural models that are invoked by different institutional contexts (Hallett and Ventresca, 2006; Harding, 2007).

A second line of work demonstrates that people, especially in complex modern societies, acquire a capacity for polyculturalism stemming from their chronic exposure to multiple and incongruent institutional orders. The normative assumptions governing relationships in the family, for example, are very different from those governing market transactions (Friedland and Alford, 1991). Consequently, people habitually draw symbolic boundaries between familial and economic relationships to resolve this incongruence (Zelizer, 2007).

Extending these arguments across levels of analysis, institutional sociologists have similarly proposed that organizations, like individuals, often operate in multi-institutional environments (Boltanski and Thévenot, 2006). For example, many companies cultivate a family-like ethos but draw on a market logic to manage labor relations. Employees intersect the different cultural orders upon which such organizations are founded. Medical professionals, for example, are required to navigate the tensions between competing cultural logics that understand medicine either through the lens of science or care-giving. The former emphasizes scientific authority and diagnostic success, whereas the latter conceptualizes quality health care as compassionate and preventive. Each prescribes different criteria for evaluating the legitimacy and desirability of behaviors and outcomes (Dunn and Jones, 2010). Institutional plurality begets friction and fragmentation in organizations when different individuals subscribe to distinct institutions, adopt different identities, and see the organizational mission through internally consistent but interpersonally incongruent lenses. Organizations can overcome this tension when their members cognitively fuse these different cultural components (Battilana and Dorado, 2010; Zilber, 2002; Besharov, 2014).

Bringing together the two broad perspectives - one that emphasizes heterogeneity's roots in 
group composition and the other that focuses on the breadth of cultural repertoires available to individual actors - we argue that cultural heterogeneity comprises two analytically distinct dimensions: interpersonal and intrapersonal. By interpersonal heterogeneity we refer to misalignment in cultural perceptions among the individuals who make up the organization. By intrapersonal heterogeneity, we mean the breadth of cultural beliefs to which those individuals subscribe.

To illustrate this distinction, we return again to our stylized example in which there exist only two possible cultural beliefs, $A$ and $B$. Figure 1 illustrates the demographic makeup of two hypothetical organizations, each represented by a circle. The organization on the left, comprising individuals who either adopt belief $A$ or belief $B$, exhibits high interpersonal heterogeneity but low intrapersonal heterogeneity. Its culture exhibits low alignment across individuals, and individuals themselves tend to subscribe to a smaller set of cultural beliefs. The organization on the right, in contrast, is characterized by high intrapersonal heterogeneity and low interpersonal heterogeneity. Individuals on average maintain a wide variety of beliefs about how to accomplish work in the organization and exhibit high alignment about the importance of those beliefs.

Distinguishing between these two components of heterogeneity helps to uncover an important insight: organizations with broad within-person cultural repertoires need not be characterized by high levels of between-person differences. Netflix, for example, has developed a variety of human resource practices that complement its broad cultural mission. The company places a strong emphasis on hiring and dismissal on the basis of cultural fit and, at the same time, institutes formal procedures and behavioral norms that are consistent with the mission and breadth of values it espouses (McCord, 2014). Netflix, in other words, invests in cultivating low interpersonal heterogeneity and high intrapersonal heterogeneity. Insofar as these practices are effective, they should produce a culture that is both consensual and broad. 


\section{Performance Implications of the Two Forms of Cultural Heterogeneity}

Seen in this light, the trade-off between organizational coordination and problem-solving capacity no longer seems inescapable. If cultural heterogeneity comprises two dimensions -interpersonal and intrapersonal - then culture can facilitate coordination without necessarily undermining creative problem-solving and innovation. Consistent with this logic, we argue that each dimension of heterogeneity should promote different organizational outcomes.

Drawing on the literature on cultural strength, we propose that interpersonal heterogeneity will weaken an organization's coordination and cohesion and will therefore undermine its capacity for effective execution. We therefore anticipate:

HYPOTHESIS 1 (H1): All else equal, interpersonal heterogeneity will be negatively related to a firm's capacity for efficient execution, as reflected in profitability.

Interpersonal heterogeneity, and its negative effects on individual and organizational performance, have been extensively researched. Hypothesis 1 is broadly consistent with prior work on cultural strength and consensus in organizations. To our knowledge, however, no prior studies have systematically compared - as we do here - differences in interpersonal heterogeneity across organizations over time and studied the implications of these differences for performance.

Unlike interpersonal heterogeneity, the intrapersonal form of cultural heterogeneity has not been previously examined in organizational research. Our core argument about intrapersonal heterogeneity is that, because creativity and innovation stem from the recombination of previously unrelated ideas, a wide cultural toolkit should — all else equal—be conducive to individual creativity (Amabile, 1988). Previous work has conceived of such recombination as arising from interpersonal exchange - that is, as a function of teams rather than of individuals (de Vaan et al., 2015). Our conceptualization of intrapersonal heterogeneity instead shifts attention to the cultural resources available to individuals and the recombinant innovation they can engage in as a result. Creative recombination is, ultimately, something that individuals do (Amabile, 1988; Sauermann and Cohen, 
2010), although organizations create contexts that can facilitate or inhibit this creativity (Taggar, 2002; Amabile et al., 1996).

Prior work on cultural heterogeneity has assumed that organizations enable creativity by forming culturally varied teams (e.g., Pieterse et al., 2013). We propose that organizations can also facilitate creativity — whether deliberately or organically — by increasing the representation of members who espouse a broad set of beliefs. Evidence for a link between intrapersonal heterogeneity and individual creativity comes from cultural psychology. Multi-cultural individuals, for example, exhibit a capacity for high integrative complexity and creative output by virtue of chronic exposure to different national cultures (Tadmor et al., 2012a).

We argue that the recombinant advantages of interpersonal cultural heterogeneity should also manifest in organizations whose members have access to broad cultural toolkits. Performing complicated tasks often requires individuals to draw upon and integrate multiple and sometimes conflicting cultural ideas about how work is or should be done. Indeed, historical accounts of inventors and entrepreneurs often place them in cultural crossroads. For example, the hackers of the early computer industry intersected the seemingly antithetical worlds of cold war military research culture and 1960s counterculture, ushering in new technologies and organizational forms to translate these technologies into products (Turner, 2010). This ability to combine multiple perspectives was presumably also conducive to creative entrepreneurship for the machine operators in Stark's (2011) study of a Hungarian factory in the late 1980s. Operating in a cultural context that valued technical skills but also promoted an anti-bureaucratic, relationship-oriented ethos, these factory workers were successful in forging innovative partnerships and pursuing semi-private enterprise under Hungary's late-communist "second-economy" legislation.

As both of these examples illustrate, organizations whose members draw on broader cultural toolkits tend to exhibit a greater capacity for creativity and innovation. In its most concrete form, we propose that this capacity will translate into patenting success. Its more intangible forms and their consequences for future growth will, we argue, instead be reflected in market valuations of a 
firm's assets. Thus, we hypothesize:

HYPOTHESIS 2 (H2): All else equal, intrapersonal heterogeneity will be positively related to a firm's capacity for creativity and innovation, as reflected in patenting success and positive market valuations.

How organizations transform innovative ideas into positive organizational outcomes differs from how they facilitate individual creativity. The generation of novel ideas requires divergent thinking and complex integration, which, we contend, can be catalyzed by intrapersonal heterogeneity. In

contrast, selecting which of these ideas to act on and doing so effectively requires other forms of information processing and problem solving capacities (Berg, 2016). We do not hypothesize about the group processes that enable teams to translate creative ideas into organizational outcomes, as those have been studied elsewhere (e.g., Woodman et al., 1993; Taggar, 2002). Rather, we posit that intrapersonal cultural heterogeneity is, ceteris peribus, conducive to innovative output through its relationship with individual creativity.

\section{Language as a Window into Cultural Heterogeneity}

In operationalizing the two constructs - interpersonal and intrapersonal heterogeneity — we begin with the premise that organizational culture can be detected in the language used by members (Pinker, 2007; Crémer et al., 2007). The relationship between language and culture is complex. A useful way of conceptualizing this relationship draws on the distinction between culture's behavioral and cognitive dimensions (Mobasseri et al., forthcoming). In the former view, language can be thought of as a set of norms that facilitate interpersonal coordination and that people adhere to when they want to fit in to an organization. Weber and Camerer (2003), for example, experimentally demonstrate that linguistic conventions formed by individuals solving a coordination task increase group efficiency but also serve as an impediment when groups with different conventions are combined. In more recent work, Srivastava et al. (2017) and Goldberg et al. (2016) develop 
a language-based measure of cultural fit and, using an email corpus and personnel records from a mid-sized firm, demonstrate that compliance with linguistic norms is positively related to individual attainment.

Yet language can also reveal a person's underlying beliefs and assumptions. For example, the language activists and civil society organizations used in public discourse reflected deep-current cultural shifts in Americans' perceptions of nuclear energy in the 1980s (Gamson and Modigliani, 1989) and of Muslims in the period following the September 11th terrorist attack (Bail, 2012). Building on these insights, we propose that organizational culture can not only be detected by observing the degree of linguistic compliance that members exhibit when communicating with each other - for example, in emails or text messages - but also in the language they use to describe the organization as a whole. In particular, we focus on the topics that members use when describing their culture to each other and to outsiders. When explicitly talking about culture, organizational members consciously articulate the assumptions and beliefs they perceive are prevalent in their organization.

Whether measuring culture based on self-reports or expressions of language, prior work has focused on specific categories, such as innovation or transparency, that were predefined by researchers or informants (e.g., senior leaders in the firm) (Ehrhart and Naumann, 2004; O'Reilly et al., 1991). For example, Luo et al. (2016) identify cultural topics such as "innovation" and "quality" in employee reviews of firms on Glassdoor (the same site from which our data are drawn) and show that different categories are correlated with employee satisfaction and corporate performance in different industries.

Although we acknowledge that certain cultural topics may matter more than others for success in a given industry sector, we propose that the distribution of cultural topics between and within individuals can nevertheless be independently related to firm profitability and innovation. The novelty of our approach is that it neither privileges one set of cultural topics over others nor assumes that researchers and informants understand the culture better than the typical organiza- 
tional member does. Instead, we assume that all topics used in discourse about the organization's culture are potentially informative.

Given a set of topics that organizational members use to describe culture in a given period, we define interpersonal heterogeneity as the dissimilarity of topics that group members mention in their characterizations. In other words, organizations exhibit greater interpersonal heterogeneity when their members diverge from one another in describing the culture. We define intrapersonal heterogeneity as the breadth of topics used in individual members' cultural descriptions. Organizations exhibit greater intrapersonal heterogeneity when their members have access to and draw from a more diverse cultural toolkit. ${ }^{2}$

\section{METHOD}

\section{Data Sources and Sample}

The data include all employer reviews written by employees in the United States from January 2008 to July 2015 on the website Glassdoor. ${ }^{3}$ Glassdoor is a career intelligence website that attracts a diverse audience primarily as a job search platform. It has an estimated 17 million unique users per month. While their identities as employees are authenticated by Glassdoor, reviewers are anonymous, thus making the reviews less susceptible to bias stemming from fear of employer retribution. Reviews are either unsolicited or contributed by users searching for jobs in exchange for unlimited site access (see Appendix B for details). Popadak (2013) used similar employee review text to construct longitudinal culture measures. ${ }^{4}$

\footnotetext{
${ }^{2}$ Although we have theorized about the independent effects of interpersonal and intrapersonal heterogeneity on firm performance, we acknowledge that the two constructs are interrelated. In fact, our empirical measures of interpersonal and intrapersonal heterogeneity are negatively correlated. We discuss why this is the case and explore the two measures' interrelationships in Appendix C.

${ }^{3}$ Accessible at www.glassdoor.com.

${ }^{4}$ Popadak's (2013) measures of organizational culture focused on specific cultural features, such as integrity, detailorientation, and adaptability, rather than the distribution of cultural content within and between employees. Nevertheless, she demonstrated that cultural attributes of organizations derived from the text of employee reviews of firms on Glassdoor are highly correlated with popular, survey-based assessments of the workplace culture. This finding helps validate the use of Glassdoor reviews as a means to assessing aspects of a firm's changing organizational culture.
} 
We restricted the firm sample to: 1) publicly-traded companies for which we have access to performance data from Compustat, and 2) firms with at least 50 employee reviews in one or more quarters to ensure that there were a sufficient number of reviews to calculate our culture measures. A small number of reviews were later dropped from this sample because they did not contain at least five words that were weighted by the LDA culture model. Only firm/quarters with at least 25 reviews were used in estimated models. The resulting sample contains 512,246 reviews across 492 organizations. We lagged all predictors by one quarter to partially alleviate concerns of reverse causality and standardized the culture measures.

\section{Measures}

\section{Dependent Variables}

Our hypotheses focus on the link between cultural heterogeneity and firms' capacity for efficient execution (H1) and creativity and innovation (H2). We link the capacity for efficient execution to firm profitability, as measured by Return on Assets (ROA) - i.e., income before extraordinary items over total assets. We link the capacity for creativity and innovation to both the market's expectation of a firm's growth potential and to patenting success.

ROA is commonly understood as a measure of profitability that is indicative of a firm's ability to effectively capitalize on its assets. We therefore use it as a reflection of a firm's capacity for efficient execution. Creativity and innovation are more challenging to measure, and we consequently rely on two types of performance indicators: market valuation and patenting output.

We measure the market's expectation of a firm's growth potential using Tobin's Q (TQ) - i.e. the market value of a firm's assets relative to their book value. Given the forward-looking nature of the market, this measure is commonly understood as an indicator of intangible capabilities and assets - from marketing prowess to innovative IT use (Bharadwaj et al., 1999). Creativity and innovation are inherently linked to Tobin's Q. Investors tend to reward companies that exhibit 
creative business strategies and that pursue technological innovation (Kogan et al., 2017). Indeed, R\&D intensity and patenting success are generally positively associated with Tobin's Q (Hall et al., 2005). Formally:

$$
T Q=\frac{\text { market value of assets }}{0.9 * \text { book value of assets }+0.1 * \text { market value of assets }}
$$

Where market value of assets is defined as:

$$
M V=\text { book assets }+ \text { (market value of common equity - common quity - deferred taxes) }
$$

While Tobin's Q broadly captures a firm's potential for growth and innovation as judged by the market, we also measure innovation more directly via patenting success. Patents mark the creation of new knowledge and are well established as important innovation outcomes (Lanjouw and Schankerman, 2004). First, we measure a firm's ability to successfully produce patents by counting the total number of patents a firm applies for within a given quarter that are later approved. Second, we measure the mean number of backward citations made by the patents in a firm's portfolio in a given quarter, which is a common indicator of the technological importance and market value of the patents (Lanjouw and Schankerman, 2004). ${ }^{5}$ Patents are required to cite relevant prior art, or backward citations to existing patents upon which the focal patent builds. We logged the mean backward citations measure to account for skew.

Although patenting is a direct measure of innovation, it is not a perfect one. First, patenting captures technological innovation that can be protected as intellectual property, but a large proportion of innovation, such as marketing creativity or business strategy, is not reflected in patenting output. Second, industries vary significantly in patenting volume. While patenting is extremely common in the pharmaceutical industry, for example, it is not in retail. Our measures of patenting,

\footnotetext{
${ }^{5}$ We lack adequate data on forward citations, another measure of technological importance that counts the number of times that focal patents are cited by subsequent patents, given the recency of the data. This is an avenue for future research.
} 
particularly patenting quality, therefore only apply to a relatively small subset of companies. Overall, we evaluate $\mathrm{H} 2$ by examining both Tobin's Q and patenting outcomes. Whereas the former is a broad but noisy measure of innovation and creativity, the latter provides a more direct but narrower indication of innovation.

\section{Language-Based Measures of Cultural Heterogeneity}

We develop language-based measures of cultural heterogeneity to capture variation in interpersonal and intrapersonal heterogeneity. We measure interpersonal heterogeneity and intrapersonal heterogeneity using free response text written by employees reviewing the firm. Following prior text analysis work, we treat each review as a "bag of words," which assumes that we can identify topical content even after discarding word order. We then represent each review as a vector of unigram counts, which identifies how many times the review includes individual words. Together, these individual words comprise a set of the most popular words that appear across the entire text corpus.

Our empirical strategy consists of two primary steps: 1) training a linguistic topic model to identify distinct dimensions of organizational culture mentioned in employee reviews across the entirety of the Glassdoor data, and 2) fitting that model to our analytic sample to identify the cultural dimensions mentioned in each employee review for the companies that we can track over time. We use a Latent Dirichlet Allocation (LDA) topic model (see Appendix A for technical details). LDA inputs a document-term matrix, for which the rows are reviews and the columns are unigram counts, and identifies distinct topics across the corpus by observing words that tend to co-occur frequently within each review. LDA then outputs a document-topic matrix, for which each review is assigned to a probabilistic mixture of topics, or a probability distribution giving the percentages across all topics $c \in C$ that the model estimates comprise the review. (For further background and empirical examples of LDA in use, see DiMaggio et al. 2013; Mohr and Bogdanov 2013; Jha and Beckman 2017; and Kaplan and Vakili 2015.) 


\section{Identifying a Set of Cultural Dimensions}

Training the LDA model allows us to learn what topics employees across all organizations in the Glassdoor data collectively consider germane to organizational culture. Our model training approach requires a key assumption: when employees write about firm culture, they sometimes explicitly use the word "culture" or a synonym and sometimes do not. Regardless, we can use the presence of a culture synonym as a label that indicates a given phrase contains content relevant to culture. Training the LDA model on text with these explicit references allows the model to identify a set of cultural topics. The model is then fit to reviews in our analytic sample to identify the cultural topics in text containing either explicit or implicit culture references (see Appendix A for details).

The LDA model requires the researcher to choose the number of topics to output. Our goal in choosing the number of topics is not maximizing the coherence or distinctiveness of the topics because we are not interested in the cultural content per se, but rather the distribution of content between and within reviewers. As such, we output a large number of topics, 500, to ensure we tease apart conceptually meaningful distinctions between cultural topics. This decision is informed by methodological research on LDA models - above some threshold, new topics only "nibble away" at existing topics rather than fundamentally alter the topic distribution. This suggests that more topics are preferable to fewer ones given our focus on the distribution of content (Wallach et al., 2009, p. 8). Our cultural heterogeneity measures are highly-correlated and our results consistent using different numbers of topics (i.e. 25, 50, 100, and 250).

The topics identified by the LDA model have face validity as cultural dimensions that capture the linguistic signatures of ideas, beliefs, and normative expectations possessed by organizational members. One way to validate LDA topics is to examine the words that are most highly weighted within each topic (DiMaggio et al., 2013). Table 1 shows the highest-weighted words for four hand-picked and four randomly selected LDA topics, as well as simple labels we chose that gen- 
erally capture the underlying meanings of the topics. The first set was hand-picked based on its highly distinctive culture content, and the randomly selected set is representative of average LDA topics. The LDA topics appear to be germane to organizational culture, lending support for our unsupervised learning approach.

After identifying cultural topics using this training set of phrases with explicit cultural references, we fit the LDA model to the reviews in our sample. In contrast to clustering methods, LDA is a mixed membership approach, which assigns each document to a probability distribution over multiple topics. Figure 2 illustrates LDA's assignment of each review in the analytic sample to a mixture of multiple culture topics, represented as a topic probability distribution over the set of cultural topics. The model predicts that two reviews with similar topic probability distributions contain similar content.

\section{Measuring Interpersonal Heterogeneity}

We measure interpersonal heterogeneity by assessing the degree to which a firm's employees in a given quarter characterize the firm using dissimilar cultural topics. (Appendix A provides a series of measurement validation checks.) After fitting the LDA model to the reviews in our analytic sample, each review $i$ is represented as a probability distribution $p$ indicating the relative proportion of each cultural topic $c$ estimated as present in the review text.

We define interpersonal heterogeneity for a given firm/quarter as the mean Jensen-Shannon (JS) divergence between the LDA probability distributions for all unordered pairs of reviews $i, j$ for that firm/quarter, formally:

$$
A=\frac{\sum_{i, j} J S\left(p_{i}, p_{j}\right)}{\sum_{i, j}}, \text { for all }\{i, j \mid i<j\}
$$


where the JS-divergence between the two probability distributions is defined as:

$$
J S\left(p_{i}, p_{j}\right)=\frac{1}{2} K L\left(p_{i}, M\right)+\frac{1}{2} K L\left(p_{j}, M\right)
$$

and where $M=\frac{1}{2}\left(p_{i}+p_{j}\right)$ and $K L\left(p_{i}, M\right)$ is the Kullback-Leibler divergence of $M$ from $p_{i}$ :

$$
K L\left(p_{i}, M\right)=\sum_{c \in C} p_{i}(c) \log _{2} \frac{p_{i}(c)}{M(c)}
$$

JS-divergence is a symmetric measure of the dissimilarity of two probability distributions. It is well-suited for comparing sparse, power-law distributions of words observed in natural language and has been used previously to measure the similarity of organizational members' language use (Goldberg et al., 2016; Srivastava et al., 2017).

\section{Measuring Intrapersonal Heterogeneity}

We measure intrapersonal heterogeneity by assessing the degree to which a firm's employees discuss a broad versus narrow set of cultural topics (see Appendix A). Each review $i$ is represented as a probability distribution $p$ indicating the relative proportion of each cultural topic $c$ estimated as present in the review text. We apply the Herfindahl index, a popular measure of concentration, to these probability distributions, and calculate the mean Herfindahl score across all reviews for a given firm/quarter. Formally:

$$
\bar{H}=\frac{\sum_{i} \sum_{c \in C}\left(p_{i}^{c}\right)^{2}}{\sum_{i}}
$$

After taking the inverse, higher values indicate that employees discuss a broader range of cultural topics, while lower values indicate a narrower, concentrated set of topics. We take the natural log of the mean Herfindahl Index because the measure has a highly skewed distribution. Intrapersonal 
heterogeneity for a firm/quarter is formally defined as::

$$
B=1-\ln \bar{H}
$$

Figure 3 provides a stylized example of how our measures of interpersonal and intrapersonal heterogeneity capture systematic differences in the LDA topic probability distributions across individual reviews within a given firm-period. Panel A illustrates that firm-periods with low interpersonal heterogeneity feature reviews with more similar topic distributions. Conversely, high interpersonal heterogeneity firm-periods have reviews with more dissimilar topic distributions. Panel B illustrates that low intrapersonal heterogeneity firm-periods have reviews with more concentrated topic distributions on average, while high intrapersonal heterogeneity firm-periods have reviews with on average more uniformly distributed topic distributions.

Our language-based model of cultural heterogeneity has two advantages over survey-based culture measures. First, it allows us to measure dimensions of organizational culture longitudinally for a large, diverse set of organizations, which would be difficult using more expensive and timeintensive survey methods. Second, the model inductively identifies topics that employees consider germane to organizational culture. We do not require the researcher to make a priori assumptions about the cultural topics that broadly characterize organizations.

Given that the employees who wrote Glassdoor reviews were not selected through random sampling from the population of firm employees, Appendix B includes robustness checks to address the impact of non-random selection of employees into writing Glassdoor reviews that could bias our findings. We find no evidence that either the number or composition of reviewers systematically changes with firm performance and no evidence that the cultural heterogeneity measures themselves vary with the number or composition of reviewers. 


\section{Analytical Strategy and Estimation}

We test our hypotheses with two types of models. The first is a conventional OLS model with lagged independent variables. (When estimating patent counts, we also use a negative binomial model.) In addition to our main independent variables, we control for firm size (measured as logged value of assets) and number of reviews (logged, to account for systematic variation in cultural heterogeneity measures attributable to the number of reviews with which they were produced). We also include industry and quarter fixed effects, given that performance outcomes vary significantly by industry and over time. We cluster standard errors by firm to allow for correlation between observations of the same firm over time.

A second type of model relies on Coarsened Exact Matching (CEM) (Iacus et al., 2012). We use CEM for two reasons. First, CEM allows us to (partially) address concerns about endogeneity. CEM identifies firm observations that vary on the culture variable of interest but have the same or very similar values for each control variable. Conditional on identifying all variables that affect the relationship between cultural heterogeneity and performance, CEM helps to correct for selection bias. We acknowledge, however, that the relationship between culture and firm performance is likely to be complicated and potentially bi-directional. CEM moves us closer to causal estimates; however, in the absence of exogenous variation in cultural heterogeneity or a compelling instrumental variable, we stop short of making a strong causal claim.

Second, we assume that a substantial proportion of variation in the effects of cultural heterogeneity on performance is attributable to differences between firms (for example, to organizations' different emphases on cultivating cultural consensus). Moreover, culture is known to change slowly within firms. Although our data are comprehensive, they only afford systematically observing within-firm cultural change over an extensive period of time for a subset of companies. To properly estimate between-firm differences it is therefore important that our modeling strategy account for other factors, such as industry, firm size and period, which may result in non-linear relationships 
between cultural heterogeneity and performance. CEM provides such a modeling approach by allowing us to match firms that are culturally different but otherwise similar.

We implemented CEM as follows. For each culture variable (interpersonal and intrapersonal heterogeneity), we first divided observations into high and low categories on the culture measure, defined by a value above or below the industry median. ${ }^{6}$ We then matched these firms identified as high or low on the culture variable with others that were the same or very similar on observed characteristics to achieve covariate balance.

CEM allows us to match exactly on some covariates and coarsely on other covariates when it is infeasible to produce exact matches. We matched exactly on industry, year, and quarter. We matched coarsely on firm assets as a firm size control and on number of reviews to account for the level of coverage on the Glassdoor website. For the firm performance outcomes and patent count, coarse matches were identified using the binning algorithm default for the cem command in Stata. ${ }^{7}$ However, the default binning algorithm did not produce enough matches for the mean backward citations outcome to run a meaningful statistical analysis since that outcome is conditional on a firm having patented in a given quarter. As such, we manually instructed the command to identify matches using five equally-spaced bins with respect to firm assets, and three equally-spaced bins with respect to the number of reviews.

This procedure produced enough matches for analysis while also achieving balance on the covariates. An attractive feature of CEM is that it can produce matched strata with an unequal number of high and low culture observations so as to maximize the total number of matched observations and thus increase estimation efficiency in the subsequent analysis. The CEM algorithm produces simple weights to adjust for these differences during estimation, which we apply in all models. We also include strata fixed effects in all models - in other words, we model variation in the

\footnotetext{
${ }^{6}$ We identify high and low culture groups using industry medians because the distributions of interpersonal and intrapersonal heterogeneity vary substantially across some industries, where industry is defined by two-digit SIC code.

${ }^{7}$ Sturge's rule is the default algorithm, which is commonly used to determine the bin width when representing a probability distribution as a histogram.
} 
performance outcomes between high and low culture observations within each stratum of matched observations. Finally, we once again cluster standard errors by firm to allow for correlation between observations of the same firm over time.

\section{RESULTS}

Table 2 reports univariate statistics and bivariate correlations for the final analytical sample. Interpersonal heterogeneity and intrapersonal heterogeneity have a moderately high negative correlation. Consistent with Hypothesis 1, interpersonal heterogeneity has a significant negative association with ROA. Consistent with Hypothesis 2, intrapersonal heterogeneity has a significant positive correlation with Tobin's Q and patenting. Additionally, interpersonal heterogeneity has a moderately high positive correlation with firm size, and intrapersonal heterogeneity has a negative correlation with the number of GlassDoor reviews.

We report both OLS and CEM model results as our main findings. The matching strategy is successful in that it eliminates statistically significant differences in the observed covariates for observations with non-missing data across the four outcome variables. Table 3 shows t-tests on covariate means before versus after matching for both the interpersonal heterogeneity and intrapersonal heterogeneity matching across the four outcomes. Any large t-statistics for firm assets and number of Glassdoor reviews that exist before matching are sharply reduced to the point of non-significance after matching.

Table 4 shows regression results for models of ROA on interpersonal heterogeneity as tests of Hypothesis 1. Model 1 shows that interpersonal heterogeneity has a significantly negative association with ROA in an OLS specification with quarter and industry fixed effects. Model 2 shows that the negative association holds in the matched sample. Thus, we find support for Hypothesis 1: firms higher in interpersonal heterogeneity exhibit lower profitability. 
Table 5 shows regressions results for models of Tobin's $Q$ and the patenting outcomes on intrapersonal heterogeneity. Model 1 shows that intrapersonal heterogeneity has a significantly positive association with Tobin's Q in an OLS specification with quarter and industry fixed effects. This positive association holds in Model 2 using the matched sample. Model 3 shows that higher intrapersonal heterogeneity predicts greater patenting volume in an OLS specification. We also modeled the raw patent count in a negative binomial specification in Model 4, which produces consistent results. Model 5 shows that this effect of intrapersonal heterogeneity on patenting volume holds with the matched sample. We find in Model 6 that higher intrapersonal heterogeneity is associated with higher mean backward citations among the patents in a firm portfolio. This association holds in Model 7 using the matched sample. Together, these results provide support for Hypothesis 2: firms higher in intrapersonal heterogeneity exhibit a greater capacity for creativity and innovation as reflected in their increased market valuation, larger patenting volume and higher patent quality.

Figure 4 provides a visualization of the predicted effects of interpersonal and intrapersonal heterogeneity on the firm performance and patent outcomes for our CEM models. A one standard deviation increase in interpersonal heterogeneity reduces ROA by approximately $0.35 \%$, which is equivalent to 0.13 standard deviations (Panel A). A one standard deviation increase in intrapersonal heterogeneity increases Tobin's Q by approximately 0.25 points, or 0.15 standard deviations (Panel B); increases patent count by roughly 0.2 , or approximately 0.07 standard deviations (Panel C); and increases mean backward citations by approximately 0.28 , or 0.25 standard deviations (Panel D).

Appendix $\mathrm{C}$ describes a series of alternative models that we use to explore the interrelationships between the two heterogeneity measures. We show that our main results for each heterogeneity measure hold when we control for the other measure and find no evidence of cross-effects (i.e., interpersonal heterogeneity affecting growth/innovation or intrapersonal heterogeneity influencing productivity). Second, although we do not find evidence of a linear interaction effect between the heterogeneity measures, we present some preliminary findings based on indicator variables that 
point to possible non-linear interrelationships, suggesting that this may be a promising avenue for future research.

\section{DISCUSSION AND CONCLUSION}

This article has sought to bring conceptual clarity and empirical evidence on a longstanding question in organizational research: when is a diversity of ideas and beliefs beneficial for organizational success and when is it instead detrimental? From a perspective that understands organizations as solutions to complex coordination problems, cultural heterogeneity is mostly seen as a source of dissonance and friction. In contrast, through the lens of economic and cultural sociology, it is viewed as a necessary condition for creativity and innovation.

We propose that this tension can be resolved when we consider the duality in diversity - that it can take two analytically distinct forms. Prior research has emphasized heterogeneity between organizational members but mostly overlooked the heterogeneity that can exist within individuals. We conceptually separate the two forms and argue that interpersonal heterogeneity - the extent to which organizational members diverge in their understanding of firm culture - is negatively associated with effective coordination and execution, whereas intrapersonal heterogeneity - the breadth of cultural beliefs about the organization that are held by members - is positively linked to creativity and the capacity for recombinant innovation. We further propose that the two forms of heterogeneity will be tied to different organizational outcomes and report evidence of a negative link between interpersonal heterogeneity and a firm's subsequent return on assets, as well as a positive relationship between intrapersonal heterogeneity and a firm's Tobin's Q and patenting activity. 


\section{Organizational Culture and Firm Performance}

Findings from this investigation make several noteworthy contributions to the extensive and multidisciplinary literature that examines the link between organizational culture and firm performance (e.g., Sørensen, 2002; Van den Steen, 2010; Kotter, 2008). First, whereas much of this work has examined how specific cultural content-for example, norms of adaptability - relate to outcomes such as cash flow growth (Chatman et al., 2014), we demonstrate that the distribution of culture within an organization can have performance consequences that are independent of the organization's specific cultural content (cf. Harrison and Carroll, 2006). Our findings neither invalidate nor downplay the importance of studies that focus on specific organizational culture features. Yet the cultural content that matters for organizational success is known to vary considerably across competitive contexts (such as industry, geography, or regulatory environment). In contrast, a distributive approach to measuring culture such as ours uncovers linkages between culture and performance that would appear to be more generalizable across competitive contexts and over time.

Drawing on the sociological conceptualization of culture as toolkit, we introduce to this literature a novel organizational culture construct: intrapersonal heterogeneity. Prevailing approaches to studying organizational culture have exclusively explored cultural heterogeneity through an interpersonal lens. Constructs such as cultural strength focus on the degree of normative consensus between organizational members and the intensity with which these norms are enforced interpersonally (Chatman and O'Reilly, 2016). In other words, cultural heterogeneity is assumed to inhere in differences between individuals. Heterogeneity within individuals has been largely overlooked by this literature. Indeed, existing measures and analytical models of cultural heterogeneity are not designed to provide the data that would be needed to measure within-person heterogeneity. For example, the Organizational Culture Profile - a widely used instrument for assessing cultural features - requires respondents to array cultural norms on a normal-like scale (O'Reilly et al., 1991). It therefore assumes a fixed within-person distribution of culture. Similarly, formal models of cul- 
tural distribution in organizations (e.g. Carroll and Harrison, 1998; March, 1991) often focus on interpersonal transmission, reducing culture to a unidimensional scale.

We identify a complementary dimension of heterogeneity - that which exists within peopleand demonstrate that considering the two forms in tandem helps to resolve the ambiguity that previously existed in the literature about how cultural heterogeneity relates to firm performance. Indeed, our findings suggest that the heterogeneity tradeoff assumed in previous research - that heterogeneity harms execution and productivity but helps creativity and innovation-may, in fact, be escapable. Insofar as firms can increase intrapersonal heterogeneity while holding interpersonal heterogeneity constant, our theory predicts that they will achieve greater innovation output without sacrificing short-term profitability. Conversely, if firms can decrease interpersonal heterogeneity without eroding its intrapersonal counterpart, we anticipate that they can improve profitability without compromising innovativeness. Exploratory findings reported in Appendix C seem to point in this direction.

The identification of two analytically distinct forms of cultural heterogeneity naturally raises questions about how deliberative organizational change efforts influence each dimension and how the two relate to each other over time. An extensive literature has explored the organizational determinants of strong, interpersonally homogeneous cultures. In contrast, because intrapersonal heterogeneity is a novel construct, its antecedents remain unclear. Nevertheless, previous work suggests that disparate cultural logics can be fused together when practices embody multiple meanings (e.g., Zilber, 2002) and that organizations can influence this process through hiring and socialization (e.g., Battilana and Dorado, 2010). It remains to be studied which organizational processes are effective at facilitating intrapersonal heterogeneity and how intentional attempts to broaden organizational members cultural toolkits affect interpersonal heterogeneity. Might a deliberate focus on increasing within-person heterogeneity provide greater scope for shared understanding between people or instead sew interpersonal cultural discord? Conversely, how do managerial efforts aimed at diversifying the cultural makeup of a companys workforce affect intrapersonal heterogeneity? 
Under what conditions are the two forms of heterogeneity positively versus negatively correlated?

In the future, questions such as these will be easier to answer because of the methodological innovation we introduce: using unsupervised learning to identify cultural content in the language employees use to describe their organizations and deriving time-varying measures of organizational culture based on this language. Unlike traditional survey-based measures of culture, languagebased measures of culture can be produced unobtrusively on a continuous basis and at scale. Whereas recent work in this vein has mined internal employee communications to characterize how individuals fit in culturally within their organization (Goldberg et al., 2016; Srivastava et al., 2017; Doyle et al., 2017), the approach we develop here enables us to characterize the culture of the organization as a whole, to make comparisons across organizations, and to systematically track distributive cultural change within and across organizations.

\section{Culture as Toolkits}

Our work also injects greater theoretical precision to the theory of culture as toolkit (Swidler, 1986, 2013), which is one of the most influential perspectives in contemporary cultural sociology but also one that has been criticized as vague and susceptible to slippage in terminology (Lamont, 1992; Small et al., 2010). First, our intrapersonal heterogeneity construct represents a concrete manifestation of the somewhat hazy "symbols, stories, rituals, and worldviews" that constitute toolkits in Swidler's (1986: 273) theory. Although we acknowledge that toolkits may include a broader set of implements, we propose that a useful way to conceptualize toolkits - at least in the organizational context - is to focus on the breadth of topics employees draw upon in describing their organization's culture.

Second, our approach offers a way to extend cultural toolkits to organizations and the fields in which they are embedded (Weber, 2005). Our method can be readily adapted to characterizing

the (changing) distance between firms in the space of cultural topics. Complementing cultural compatibility analyses based on surveys (Stahl and Voigt, 2008), formal models (Van den Steen, 
2010), and laboratory experiments (Weber and Camerer, 2003), language-based measures of cultural similarity between firms could be used to examine how culture influences success or failure at the interorganizational level—for example, in mergers and acquisitions, (Bauer and Matzler, 2014; Stahl and Voigt, 2008; Van den Steen, 2010; Weber and Camerer, 2003), joint ventures, and alliances (Park and Ungson, 1997; Pothukuchi et al., 2002). Such measures could also be used to examine how the cultural distinctiveness or similarity of an organization relates to its strategic positioning and competitive advantage. Moreover, our measures can be aggregated to the field or industry level as a means to explore how toolkit breadth and composition relate to field-level dynamics.

Finally, whereas toolkit theory focuses on the repertoire of cultural resources individuals draw upon to construct strategies of action, we make the micro-to-macro link between individual toolkits, group creativity, and organizational-level outcomes. While the image of culture as toolkit has been widely influential in sociology, few studies have examined the relationship between the breadth of cultural toolkits and group-level outcomes. We argue that individuals with broad cultural repertoires are more likely to engage in recombinant innovation and demonstrate that this breadth is linked to organizational creativity and innovation. While our empirical examination focuses on for-profit organizations, we see no reason why it should not extend to other domains. To the same extent that community-level ethnic integration relates to entrepreneurship and innovation (e.g. Samila and Sorenson, 2017), our findings suggest that communities - whether at the local or national level—whose members draw on a wide range of cultural elements will exhibit, all else equal, a greater capacity for innovation.

\section{Cultural Heterogeneity and Group Diversity}

Although our conceptual arguments are not directly derived from research on relational demography and group diversity, we identify a number of important parallels between the two bodies of work. First, our distinction between the interpersonal and intrapersonal forms of cultural heterogeneity echoes Bunderson and Sutcliffe's (2002) separation of dominant function diversity (a 
between-person comparison of functional expertise on a team) from intrapersonal functional diversity (based on within-person functional breadth). Our theory takes this distinction, which has been conceptualized at the level of work groups, and extends it to the organization as a whole.

At the same time, the constructs we have developed at the organizational level have implications for research on group effectiveness. Prior work focusing on cultural diversity in groups and teams has examined surface-level traits such as race and nationality, as well as deep-level values that are measured using proxies such as the national-cultural distance between group members (Stahl et al., 2010). As this work has demonstrated, categorical differences between individuals on dimensions such as gender or occupational background can, but often do not, relate to differences in underlying beliefs (Harrison et al., 1998). The constructs we introduce offer the potential to more directly assess cultural diversity in groups. It remains to be explored how intrapersonal and interpersonal heterogeneity in work groups might relate to mechanisms such as group conflict, creativity, and social integration through which diversity - both ascribed and internalized - affects team performance.

\section{Limitations and Future Directions}

Given the nature of the data we analyze, this study has certain limitations, which also point to avenues for future research. First, the coarsened exact matching approach we use (Iacus et al., 2012) achieves balance between our treatment and control groups by matching on observed firm attributes. It does not, however, address potential threats to causal identification stemming from unobserved heterogeneity. Future research in this vein - especially studies that draw on data sets spanning longer time horizons and thus affording a window into changing firm cultures - could account for time-invariant unobserved heterogeneity by estimating within-firm models. Over the time horizon of our data set, employee descriptions of firm culture in Glassdoor reviews simply do not exhibit sufficient temporal variance to support the use of within-firm estimates.

In addition, although we report robustness checks that help to dispel concerns that our findings 
can be accounted for by compositional shifts in the kinds of employees who choose to comment about firm culture prior to changes in firm performance, we cannot fully rule out the potentially confounding role of selection effects. We leave to future research the task of more thoroughly accounting for selection dynamics in employee reviews. For example, researchers could draw on national survey panels to identify a representative set of employees at firms included in the Glassdoor data and ask them to rate their firm using the same pro and con questions used by Glassdoor.

\section{Conclusion}

This study paves the way for novel investigations of the role of culture in organizational performance. Drawing on language as a window into organizational culture, it demonstrates that cultural heterogeneity can be a double-edged sword, with its interpersonal form foreshadowing a decline in profitability and its intrapersonal form heralding heightened market expectations of future firm growth and innovative output. At the same time, it highlights that the coordination-creativity trade-off that culture presumably embodies is not inexorable. Understanding the duality in cul-

tural diversity may help uncover organizational practices and interventions that simultaneously promote efficiency and innovation. 


\section{References}

Amabile, T. M.

1988. A model of creativity and innovation in organizations. Research in organizational behavior, 10(1):123-167.

Amabile, T. M.

1996. Creativity in context: Update to the social psychology of creativity. Hachette UK.

Amabile, T. M., R. Conti, H. Coon, J. Lazenby, and M. Herron

1996. Assessing the work environment for creativity. Academy of management journal, 39(5):1154-1184.

Bail, C. A.

2012. The fringe effect civil society organizations and the evolution of media discourse about islam since the september 11th attacks. American Sociological Review, 77(6):855-879.

Battilana, J. and S. Dorado

2010. Building sustainable hybrid organizations: The case of commercial microfinance organizations. Academy of Management Journal, 53(6):1419-1440.

Bauer, F. and K. Matzler

2014. Antecedents of m\&a success: The role of strategic complementarity, cultural fit, and degree and speed of integration. Strategic management journal, 35(2):269-291

Berg, J. M.

2016. Balancing on the creative highwire: Forecasting the success of novel ideas in organizations. Administrative Science Quarterly, 61(3):433-468.

Besharov, M. L.

2014. The relational ecology of identification: How organizational identification emerges when individuals hold divergent values. Academy of Management Journal, 57(5):1485-1512.

Bharadwaj, A. S., S. G. Bharadwaj, and B. R. Konsynski

1999. Information technology effects on firm performance as measured by tobin's q. Management science, 45(7):1008-1024.

Blei, D. M., A. Y. Ng, and M. I. Jordan

2003. Latent dirichlet allocation. Journal of machine Learning research, 3(Jan):993-1022.

Boltanski, L. and L. Thévenot

2006. On justification: Economies of worth. Princeton University Press.

Bunderson, J. S. and K. M. Sutcliffe

2002. Comparing alternative conceptualizations of functional diversity in management teams: Process and performance effects. Academy of management journal, 45(5):875-893. 
Burt, R. S., M. Guilarte, H. J. Raider, and Y. Yasuda

2000. Competition, contingency, and the external structure of markets. In The new institutionalism in strategic management, Pp. 167-217. Emerald Group Publishing Limited.

Carroll, G. R. and J. R. Harrison

1998. Organizational demography and culture: Insights from a formal model and simulation. Administrative Science Quarterly, Pp. 637-667.

Chatman, J. A., D. F. Caldwell, C. A. O'Reilly, and B. Doerr

2014. Parsing organizational culture: How the norm for adaptability influences the relationship between culture consensus and financial performance in high-technology firms. Journal of Organizational Behavior, 35(6):785-808.

Chatman, J. A. and C. A. O'Reilly

2016. Paradigm lost: Reinvigorating the study of organizational culture. Research in Organizational Behavior, 36:199-224.

Crémer, J., L. Garicano, and A. Prat

2007. Language and the theory of the firm. The Quarterly Journal of Economics, 122(1):373-407.

de Vaan, M., B. Vedres, and D. Stark

2015. Game changer: The topology of creativity. American Journal of Sociology, 120(4):11441194.

Denison, D. R.

1984. Bringing corporate culture to the bottom line. Organizational dynamics, 13(2):5-22

Denison, D. R. and A. K. Mishra

1995. Toward a theory of organizational culture and effectiveness. Organization Science, 6(2):204223.

DiMaggio, P.

1997. Culture and cognition. Annual review of sociology, 23(1):263-287.

DiMaggio, P., M. Nag, and D. Blei

2013. Exploiting affinities between topic modeling and the sociological perspective on culture: Application to newspaper coverage of us government arts funding. Poetics, 41(6):570-606.

Doyle, G., A. Goldberg, S. B. Srivastava, and M. C. Frank

2017. Alignment at work: Using language to distinguish the internalization and self-regulation components of cultural fit in organizations. Stanford University Working Paper.

Dunn, M. B. and C. Jones

2010. Institutional logics and institutional pluralism: The contestation of care and science logics in medical education, 1967-2005. Administrative Science Quarterly, 55(1):114-149. 
Ehrhart, M. G. and S. E. Naumann

2004. Organizational citizenship behavior in work groups: A group norms approach. Journal of Applied Psychology, 89(6):960-974.

Fiol, C. M.

1994. Consensus, diversity, and learning in organizations. Organization Science, 5(3):403-420.

Fleming, L.

2001. Recombinant uncertainty in technological search. Management Science, 47(1):117-132.

Friedland, R. and R. R. Alford

1991. Bringing society back in: Symbols, practices and institutional contradictions. In The New Institutionalism in Organizational Analysis, W. W. Powell and P. J. DiMaggio, eds. Chicago: University of Chicago Press.

Gamson, W. A. and A. Modigliani

1989. Media discourse and public opinion on nuclear power: A constructionist approach. American journal of sociology, 95(1):1-37.

Goldberg, A., S. B. Srivastava, V. G. Manian, and C. Potts

2016. Fitting in or standing out? the tradeoffs of structural and cultural embeddedness. American Sociological Review, 81(6):1190-1222.

Gordon, G. G. and N. DiTomaso

1992. Predicting corporate performance from organizational culture. Journal of management studies, 29(6):783-798

Hall, B. H., A. Jaffe, and M. Trajtenberg

2005. Market value and patent citations. RAND Journal of economics, Pp. 16-38.

Hallett, T. and M. J. Ventresca

2006. Inhabited institutions: Social interactions and organizational forms in gouldners patterns of industrial bureaucracy. Theory and Society, 35(2):213-236.

Harding, D. J.

2007. Cultural context, sexual behavior, and romantic relationships in disadvantaged neighborhoods. American Sociological Review, 72(3):341-364.

Harrison, D. A., K. H. Price, and M. P. Bell

1998. Beyond relational demography: Time and the effects of surface-and deep-level diversity on work group cohesion. Academy of management journal, 41(1):96-107.

Harrison, J. R. and G. R. Carroll

2006. Culture and Demography in Organizations. Princeton, NJ: Princeton Univ Press. 
Iacus, S. M., G. King, G. Porro, and J. N. Katz

2012. Causal inference without balance checking: Coarsened exact matching. Political analysis, Pp. $1-24$

Jehn, K. A., G. B. Northcraft, and M. A. Neale

1999. Why differences make a difference: A field study of diversity, conflict and performance in workgroups. Administrative science quarterly, 44(4):741-763.

Jha, H. K. and C. M. Beckman

2017. A patchwork of identities: Emergence of charter schools as a new organizational form. In Emergence, Pp. 69-107. Emerald Publishing Limited.

Kaplan, S. and K. Vakili

2015. The double-edged sword of recombination in breakthrough innovation. Strategic Management Journal, 36(10):1435-1457.

Kogan, L., D. Papanikolaou, A. Seru, and N. Stoffman

2017. Technological innovation, resource allocation, and growth. The Quarterly Journal of Economics, 132(2):665-712.

Kotrba, L. M., M. A. Gillespie, A. M. Schmidt, R. E. Smerek, S. A. Ritchie, and D. R. Denison 2012. Do consistent corporate cultures have better business performance? exploring the interaction effects. Human Relations, 65(2):241-262.

Kotter, J. P.

2008. Corporate culture and performance. Simon and Schuster.

Kotter, J. P. and J. L. Heskett

1992. Corporate Culture and Performance. New York: Free Press.

Kreps, D. M.

1996. Corporate culture and economic theory. Firms, Organizations and Contracts, Oxford University Press, Oxford, Pp. 221-275.

Kunda, G.

2009. Engineering Culture: Control and Commitment in a High-Tech Corporation. Temple University Press.

Lamont, M. . .

1992. Money, morals, and manners: The culture of the French and the American upper-middle class. University of Chicago Press.

Lanjouw, J. O. and M. Schankerman

2004. Patent quality and research productivity: Measuring innovation with multiple indicators. The Economic Journal, 114(495):441-465. 
Lant, T. K. and S. J. Mezias

1992. An organizational learning model of convergence and reorientation. Organization science, $3(1): 47-71$

Lau, D. C. and J. K. Murnighan

1998. Demographic diversity and faultlines: The compositional dynamics of organizational groups. Academy of Management Review, 23(2):325-340.

Luo, N., Y. Zhou, and J. Shon

2016. Employee satisfaction and corporate performance: Mining employee reviews on glassdoor.com.

March, J. G.

1991. Exploration and exploitation in organizational learning. Organization Science, 2(1):71-87.

Marinescu, I., N. Klein, A. Chamberlain, and M. Smart

2018. Incentives can reduce bias in online.

Martin, J.

1992. Cultures in Organizations: Three Perspectives. Oxford University Press.

McCord, P.

2014. How netflix reinvented hr. Harvard Business Review, 92(1):70-76.

Mobasseri, S., A. Goldberg, and S. B. Srivastava

forthcoming. What is cultural fit? from cognition to behavior (and back). In The Oxford Handbook of Cognitive Sociology, W. Brekhus and G. Ignatow, eds. Oxford: Oxford University Press.

Mohr, J. W. and P. Bogdanov

2013. Introductiontopic models: What they are and why they matter.

Morris, M. W., C.-y. Chiu, and Z. Liu

2015. Polycultural psychology. Annual Review of Psychology, 66:631-659.

O'Reilly, C. A., J. Chatman, and D. F. Caldwell

1991. People and organizational culture: a profile comparison approach to assessing personorganization fit. Academy of Management Journal, 34(3):487-516.

Page, S. E.

2007. The Difference: How the Power of Diversity Creates Better Groups, Firms, Schools, and Societies. Princeton University Press. Google-Books-ID: FAFVHnJ7uK0C.

Park, S. H. and G. R. Ungson

1997. The effect of national culture, organizational complementarity, and economic motivation on joint venture dissolution. Academy of Management journal, 40(2):279-307 
Pettigrew, A. M.

1979. On studying organizational cultures. Administrative Science Quarterly, 24(4):570-581.

Pfeffer, J.

1983. Organizational demography. Research in organizational behavior.

Pieterse, A. N., D. Van Knippenberg, and D. Van Dierendonck

2013. Cultural diversity and team performance: The role of team member goal orientation. Academy of Management Journal, 56(3):782-804.

Pinker, S.

2007. The Stuff of Thought: Language as a Window into Human Nature. New York: Viking.

Popadak, J. A.

2013. A corporate culture channel: How increased shareholder governance reduces firm value.

Pothukuchi, V., F. Damanpour, J. Choi, C. C. Chen, and S. H. Park

2002. National and organizational culture differences and international joint venture performance. Journal of international business studies, 33(2):243-265 0047-8210.

Samila, S. and O. Sorenson

2017. Community and capital in entrepreneurship and economic growth. American Sociological Review, 82(4):770-795.

Sauermann, H. and W. M. Cohen

2010. What makes them tick? employee motives and firm innovation. Management Science, 56(12):2134-2153.

Schein, E. H.

2010. Organizational Culture and Leadership, 4th edition edition. San Francisco, CA: JosseyBass.

Small, M. L., D. J. Harding, and M. ..-. Lamont

2010. Reconsidering culture and poverty.

Sørensen, J. B.

2002. The strength of corporate culture and the reliability of firm performance. Administrative Science Quarterly, 47(1):70-91.

Srivastava, S. B., A. Goldberg, V. G. Manian, and C. Potts

2017. Enculturation trajectories: Language, cultural adaptation, and individual outcomes in organizations. Management Science, Published online in Articles in Advance 02 Mar 2017(0):null.

Stahl, G. K., M. L. Maznevski, A. Voigt, and K. Jonsen

2010. Unraveling the effects of cultural diversity in teams: A meta-analysis of research on multicultural work groups. Journal of international business studies, 41(4):690-709. 
Stahl, G. K. and A. Voigt

2008. Do cultural differences matter in mergers and acquisitions? a tentative model and examination. Organization science, 19(1):160-176

Stark, D.

2011. The sense of dissonance: Accounts of worth in economic life. Princeton University Press.

Swidler, A.

1986. Culture in action: Symbols and strategies. American sociological review, Pp. 273-286

Swidler, A.

2001. Talk of love: How culture matters. University of Chicago Press.

Swidler, A. . X.

2013. Talk of love: How culture matters. University of Chicago Press.

Tadmor, C. T., A. D. Galinsky, and W. W. Maddux

2012a. Getting the most out of living abroad: biculturalism and integrative complexity as key drivers of creative and professional success. Journal of personality and social psychology, 103(3):520542.

Tadmor, C. T., P. Satterstrom, S. Jang, and J. T. Polzer

2012b. Beyond individual creativity: The superadditive benefits of multicultural experience for collective creativity in culturally diverse teams. Journal of Cross-Cultural Psychology, 43(3):384392.

Taggar, S.

2002. Individual creativity and group ability to utilize individual creative resources: A multilevel model. Academy of Management Journal, 45(2):315-330.

Tsui, A. S., T. D. Egan, and C. A. O'Reilly III

1992. Being different: Relational demography and organizational attachment. Administrative science quarterly, Pp. 549-579.

Turco, C.

2016. The Conversational Firm: Rethinking Bureaucracy in the Age of Social Media. Columbia University Press.

Turner, F.

2010. From counterculture to cyberculture: Stewart Brand, the Whole Earth Network, and the rise of digital utopianism. Chicago: University of Chicago Press.

Uzzi, B., S. Mukherjee, M. Stringer, and B. Jones

2013. Atypical combinations and scientific impact. Science, 342(6157):468-472. 
Van den Steen, E.

2010. Culture clash: the costs and benefits of homogeneity. Management Science, 56(10):17181738 .

Van Knippenberg, D. and M. C. Schippers

2007. Work group diversity. Annu. Rev. Psychol., 58:515-541.

Wallach, H. M., D. M. Mimno, and A. McCallum

2009. Rethinking lda: Why priors matter. In Advances in neural information processing systems, Pp. 1973-1981.

Weber, K.

2005. A toolkit for analyzing corporate cultural toolkits. Poetics, 33(3-4):227-252.

Weber, R. A. and C. F. Camerer

2003. Cultural conflict and merger failure: an experimental approach. Management Science, 49(4):400-415.

Woodman, R. W., J. E. Sawyer, and R. W. Griffin

1993. Toward a theory of organizational creativity. Academy of management review, 18(2):293321.

Zelizer, V. A.

2007. The Purchase of Intimacy. Princeton, NJ: Princeton University Press.

Zilber, T. B.

2002. Institutionalization as an interplay between actions, meanings, and actors: The case of a rape crisis center in israel. Academy of management journal, 45(1):234-254. 


\section{FIGURES}
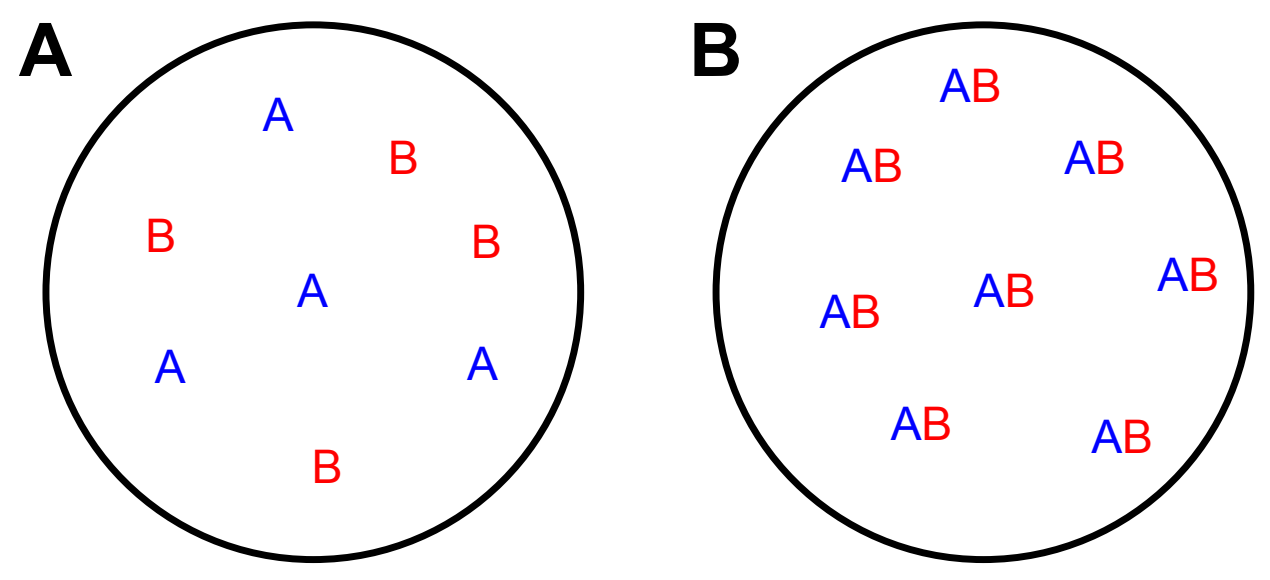

Figure 1: Example of interpersonal and intrapersonal heterogeneity. Two hypothetical organizations are represented by a circle each. Individuals making up the organization are represented by letters, corresponding to the cultural beliefs they espouse. Organization A exhibits low interpersonal and intrapersonal heterogeneity, whereas organization B exhibits high interpersonal and intrapersonal heterogeneity. 
Figure 2: Stylized Example of LDA's Mixed Membership Topic Assignment May 8, 2008

"VMware is a fun place to be; it's aggressively growing, and it

strives to provide a comfortable work environment"

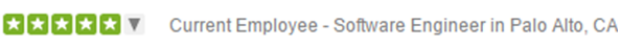

Recommends Approves of CEO

Pros

VMware is a fun place to be during the day. The company is growing, and their technology has lots of room to grow and improve. The employees are diverse in age and culture; and everyone is friendly. This is helpful as many of us are new to the Bay Area. Everyone in the company is smart, works hard, and pulls their weight. There's a culture of collaboration, and a degree of freedom in selecting one's work. VMware provides a great set of on-site perks. free soda \& other healthy beverages, on-site expresso machines, plenty of healthy snacks, pinball machines, a friday "beer bash", and plenty of games like pool, ping-pong, and foosball tables.

Show Less

Topic Probability Distribution

Cons

Although virtualization is an interesting and exciting field; some of the periphery work can be burdensome. Because the stock is volatile; recent hires will become very wealthy before other employees who have stock options that are severely underwater. Some employees underestimate the tangible advantages of competitors' products; like Parallels and Microsoft HyperV. Occasionally, perks are changed without employee involvement; to the chargin of those who chose VMware for a specific perk. A weakness is that VMware's products built by Unix people are difficult for Windows/Mac-centric users; and products built by Windows people are difficult for Unix/Mac-centric users. The cubicle areas can be noisy

Show Less

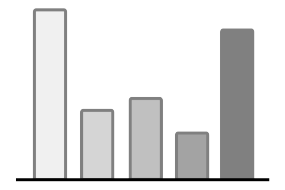

Figure 3: Stylized Example of the Two Dimensions of Cultural Heterogeneity A

B

Review

Low Interpersonal Hetero. Firm/Period

High Interpersonal Hetero. Firm/Period
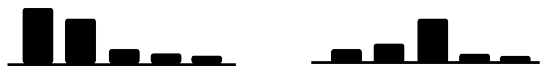

2

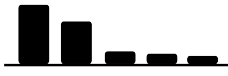

3

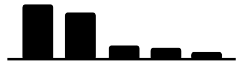

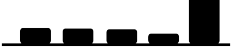

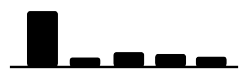

Review

Low Intrapersonal Hetero. Firm/Period

High Intrapersonal Hetero.

Firm/Period

1
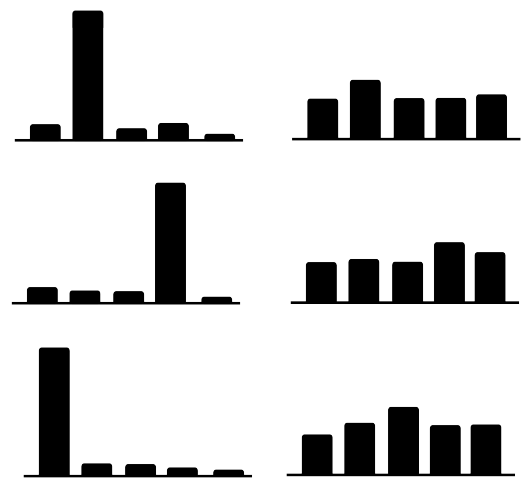
Figure 4: Predicted Effects from CEM Models of Interpersonal and Intrapersonal Heterogeneity on Firm Performance and Patent Outcomes

\section{A}

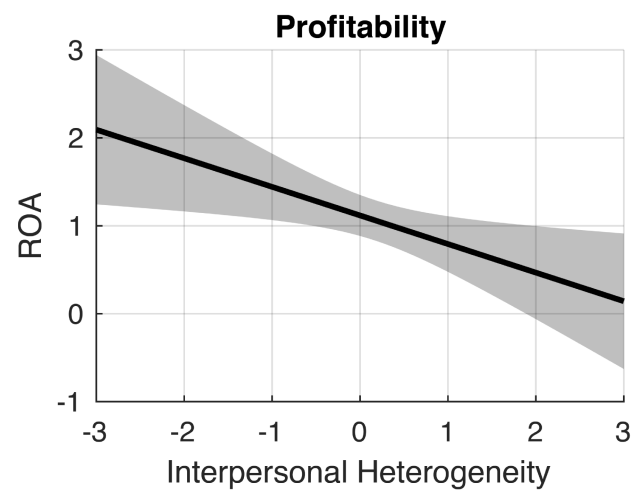

C

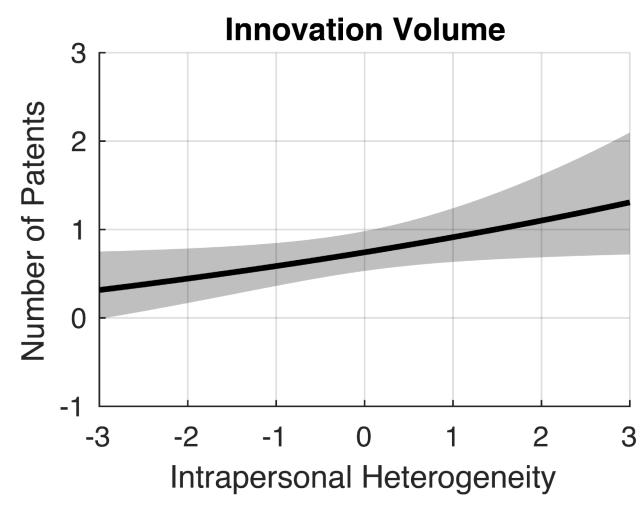

B
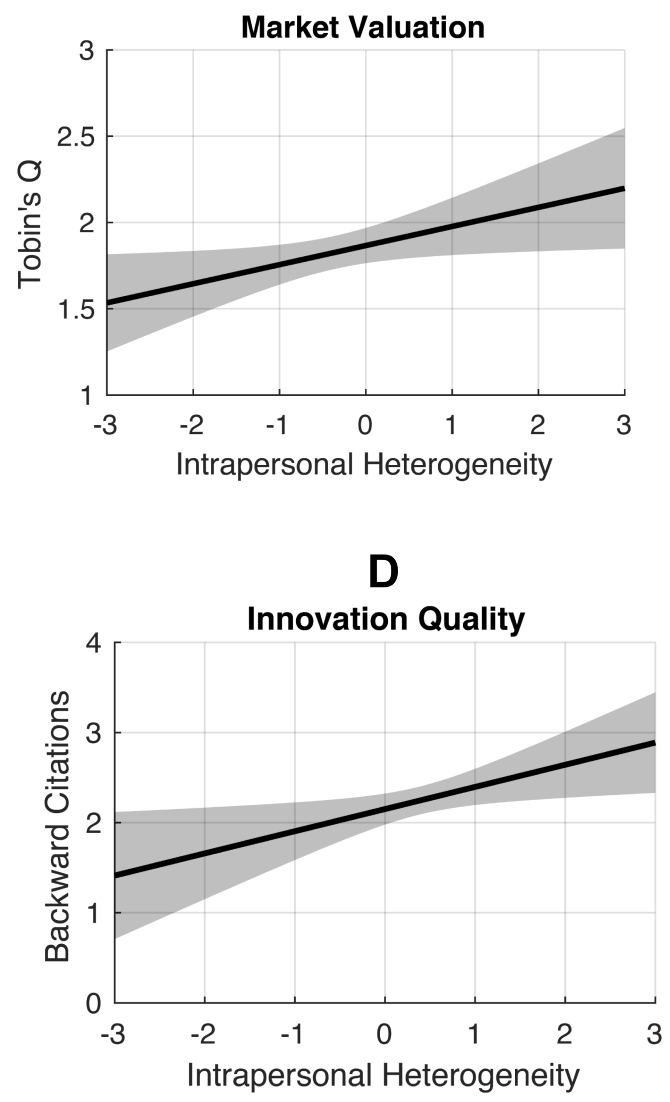


\section{TABLES}

Table 1: Highest-Weighted Words for Selected LDA Culture Topics

\begin{tabular}{c|c|l}
\hline \hline Selected Topic \# & \multicolumn{1}{c}{ Label } & \multicolumn{1}{c}{ Words } \\
\hline 10 & production quality v. quantity & $\begin{array}{l}\text { qualiti product high produc deliv commit counter de- } \\
\text { liveri emphasi quantiti }\end{array}$ \\
\hline 16 & entrepreneurial norms & $\begin{array}{l}\text { entrepreneuri thrive initi spirit dynam motiv collabor } \\
\text { starter creativ individu }\end{array}$ \\
\hline 33 & travel and multiculturalism & $\begin{array}{l}\text { travel opportun world countri meet experi chanc in- } \\
\text { teract abroad global }\end{array}$ \\
\hline 35 & social interaction & $\begin{array}{l}\text { social fun event activ interact lot frequent aspect reg- } \\
\text { ular includ }\end{array}$ \\
\hline \hline Random Topic \# & \multicolumn{1}{|c}{ Label } & $\begin{array}{l}\text { perform reward recognit recogn incent individu con- } \\
\text { sist mediocr contribut resul }\end{array}$ \\
\hline 473 & performance recognition \\
415 & organizational structure & $\begin{array}{l}\text { compani exist virtual anymor bought parent basic } \\
\text { built longer sold }\end{array}$ \\
\hline 399 & fun work environment & $\begin{array}{l}\text { fun cowork great cool amaz outgo hang toy lightheart } \\
\text { easygo brilliant train hip } \\
\text { challeng work interest reward present demand inher } \\
\text { tackl workplac }\end{array}$ \\
\hline 481 & workplace challenges \\
\hline
\end{tabular}


Table 2: Univariate Statistics and Bivariate Correlations

\begin{tabular}{lccccccccc}
\hline \hline & Mean & S.D. & \# Obs. & $(1)$ & $(2)$ & $(3)$ & $(4)$ & $(5)$ & $(6)$ \\
\hline 1. ROA & 1.52 & 2.52 & 2595 & 1 & & & & \\
2. TQ & 1.77 & 0.76 & 2595 & $0.46^{* * *}$ & 1 & & & \\
3. Patent Count & 16.20 & 65.35 & 2595 & $0.15^{* * *}$ & $0.064^{* *}$ & 1 & & \\
4. Lag Interpersonal Hetero. & 0.04 & 0.93 & 2595 & $-0.22^{* * *}$ & $-0.31^{* * *}$ & $-0.059^{* *}$ & 1 & \\
5. Lag Intrapersonal Hetero. & -0.05 & 0.90 & 2595 & $0.058^{* *}$ & $0.061^{* *}$ & $0.14^{* * *}$ & $-0.54^{* * *}$ & 1 & \\
6. Lag Log Assets & 10.38 & 1.91 & 2595 & $-0.15^{* * *}$ & $-0.45^{* * *}$ & $0.15^{* * *}$ & $0.42^{* * *}$ & -0.0024 & 1 \\
7. Lag Log \# Reviews & 4.76 & 0.67 & 2595 & $0.076^{* * *}$ & $0.070^{* * *}$ & -0.019 & $0.062^{* *}$ & $-0.17^{* * *}$ & $0.20^{* * *}$ \\
\hline \hline
\end{tabular}

${ }^{*} p<0.05,{ }^{* *} p<0.01,{ }^{* * *} p<0.001$

Log of Mean \# of Backward Citations not shown above since non-missing values are conditional on patenting: Mean: 2.22, S.D.: 1.01, \# Obs.: 774 
Table 3: t-Tests on Covariate Means Before and After Matching

\begin{tabular}{|c|c|c|c|}
\hline & $\begin{array}{c}\text { Before matching } \\
\text { t-test on means }\end{array}$ & & $\begin{array}{c}\text { Matched sample } \\
\text { t-test on means }\end{array}$ \\
\hline$\overline{\text { ROA }}$ & low-high interpersonal hetero. & & low-high interpersonal hetero. \\
\hline Lag Log Assets & -4.52 & & -0.75 \\
\hline Lag Log \# Reviews & -6.49 & & -0.18 \\
\hline Strata & & 2515 & \\
\hline Matched strata & & 265 & \\
\hline Multivariate L1 distance & 0.90 & & 0.66 \\
\hline Low interpersonal hetero. obs. & 1639 & & 360 \\
\hline High interpersonal hetero. obs. & 1644 & & 375 \\
\hline$\overline{T \text { TQ }}$ & low-high intrapersonal hetero. & & low-high intrapersonal hetero. \\
\hline Lag Log Assets & 0.55 & & 1.01 \\
\hline Lag Log \# Reviews & 10.40 & & 0.54 \\
\hline Strata & & 2496 & \\
\hline Matched strata & & 255 & \\
\hline Multivariate L1 distance & 0.91 & & 0.72 \\
\hline Low intrapersonal hetero. obs. & 1637 & & 337 \\
\hline High intrapersonal hetero. obs. & 1616 & & 362 \\
\hline Log \# Patents & low-high intrapersonal hetero. & & low-high intrapersonal hetero. \\
\hline Lag Log Assets & 0.74 & & 1.16 \\
\hline Lag Log \# Reviews & 10.27 & & 0.49 \\
\hline Strata & & 2537 & \\
\hline Matched strata & & 259 & \\
\hline Multivariate L1 distance & 0.92 & & 0.72 \\
\hline Low intrapersonal hetero. obs. & 1668 & & 346 \\
\hline High intrapersonal hetero. obs. & 1644 & & 368 \\
\hline \# Backward Citations per Patent & low-high intrapersonal heterogeneity & & low-high intrapersonal heterogeneity \\
\hline Lag Log Assets & 0.75 & & 1.24 \\
\hline Lag Log \# Reviews & 6.45 & & 0.77 \\
\hline Strata & & 579 & \\
\hline Matched strata & & 111 & \\
\hline Multivariate L1 distance & 0.94 & & 0.85 \\
\hline Low intrapersonal hetero. obs. & 426 & & 166 \\
\hline High intrapersonal hetero. obs. & 523 & & 189 \\
\hline
\end{tabular}


Table 4: ROA on Interpersonal Heterogeneity

\begin{tabular}{lcc}
\hline \hline & $(1)$ & $(2)$ \\
& OLS & Matched \\
\hline Lag Interpersonal Hetero. & $-0.58^{* * *}$ & $-0.33^{*}$ \\
& $(4.97)$ & $(2.47)$ \\
& & \\
Lag Log Assets & 0.20 & \\
& $(1.69)$ & \\
Lag Log \# Reviews & $0.35^{*}$ & \\
& $(2.41)$ & \\
Constant & & \\
& -1.85 & 0.39 \\
& $(1.73)$ & $(1.24)$ \\
\hline Quarter FEs & yes & no \\
Industry FEs & yes & no \\
Stratum FEs & n/a & yes \\
Firm/Quarters & 2616 & 735 \\
\hline \hline
\end{tabular}

Absolute $t$ statistics in parentheses

Standard errors clustered by firm

${ }^{*} p<0.05,{ }^{* *} p<0.01,{ }^{* * *} p<0.001$ 
Table 5: Tobin's Q/Patent Outcomes on Intrapersonal Heterogeneity

\begin{tabular}{|c|c|c|c|c|c|c|c|}
\hline & $\begin{array}{l}(1) \\
\mathrm{TQ} \\
O L S\end{array}$ & $\begin{array}{c}(2) \\
\text { TQ } \\
\text { Matched }\end{array}$ & $\begin{array}{c}(3) \\
\text { Log \# Pats. } \\
O L S\end{array}$ & $\begin{array}{c}(4) \\
\text { \# Pats. } \\
\text { Neg. Bin. }\end{array}$ & $\begin{array}{c}(5) \\
\text { Log \# Pats. } \\
\text { Matched }\end{array}$ & $\begin{array}{c}(6) \\
\text { \# Back. Cites } \\
\text { OLS }\end{array}$ & $\begin{array}{c}(7) \\
\# \text { Back. Cites } \\
\text { Matched }\end{array}$ \\
\hline Lag Intrapersonal Hetero. & $\begin{array}{c}0.10^{* *} \\
(3.09)\end{array}$ & $\begin{array}{l}0.11^{*} \\
(2.18)\end{array}$ & $\begin{array}{l}0.14^{* *} \\
(2.76)\end{array}$ & $\begin{array}{c}0.28^{* * *} \\
(3.43)\end{array}$ & $\begin{array}{l}0.094^{*} \\
(2.13)\end{array}$ & $\begin{array}{l}0.14^{* *} \\
(3.05)\end{array}$ & $\begin{array}{l}0.25^{*} \\
(2.39)\end{array}$ \\
\hline Lag Log Assets & $\begin{array}{c}-0.11^{*} \\
(2.55)\end{array}$ & & $\begin{array}{l}0.21^{* *} \\
(2.66)\end{array}$ & $\begin{array}{c}0.83^{* * *} \\
(5.89)\end{array}$ & & $\begin{array}{l}0.14^{*} \\
(2.23)\end{array}$ & \\
\hline Constant & $\begin{array}{c}2.60^{* * *} \\
(7.33)\end{array}$ & $\begin{array}{l}1.01^{* * *} \\
(10.20)\end{array}$ & $\begin{array}{c}-0.98 \\
(1.22)\end{array}$ & $\begin{array}{l}-22.5^{*} \\
(1.97)\end{array}$ & $\begin{array}{c}-0.0039 \\
(0.07)\end{array}$ & $\begin{array}{c}2.10^{* * *} \\
(4.32)\end{array}$ & $\begin{array}{c}1.01 \\
(1.60)\end{array}$ \\
\hline Quarter FEs & yes & no & yes & yes & no & yes & no \\
\hline Industry FEs & yes & no & yes & yes & no & yes & no \\
\hline
\end{tabular}

Absolute $t$ statistics in parentheses

Standard errors clustered by firm

${ }^{*} p<0.05,{ }^{* *} p<0.01,{ }^{* * *} p<0.001$ 


\section{APPENDIX A: Measuring Cultural Heterogeneity Using Latent}

\section{Dirichlet Allocation}

All analyzed text was first preprocessed according to standard text analysis conventions. We removed common stop words and punctuation, discarded word order, and stemmed the words using the Porter stemming algorithm.

To train the Latent Dirichlet Allocation (LDA) model, we constructed a document-term matrix for which the rows represent distinct sentences observed across all available reviews for all organizations that contain the word "culture" or a close synonym (environment, atmosphere, attitude, climate, value, philosophy, belief). This results in 904,613 sentences. We identify the 4,000 most popular unigrams in these sentences. Less popular words outside of this set were increasingly proper noun references, badly misspelled, or nonsense words. After we manually removed proper nouns, the document-term matrix tracked the frequency of 3,870 words.

This set of training sentences was analyzed using LDA - a model of the probabilistic generation of a text corpus. Documents are represented as random mixtures of topics, and each topic is characterized as a probability distribution over words (Blei et al., 2003). We parameterized LDA to identify 500 topics present in these culture sentences. Each topic is characterized by a weighted set of words that tend to co-occur within documents.

After identifying cultural topics using this training set of sentences with explicit cultural references, we fit the LDA model to the reviews in our analytic sample. In contrast to clustering methods, LDA is a mixed membership approach, which assigns each document to a probability distribution over multiple topics. 


\section{Measure Variation}

Organizational culture is stable but not invariant over time (Kotter and Heskett, 1992). As such, we examine the sources of variation in our measures of cultural heterogeneity. Figures A1 and A2 plot the within firm variation in interpersonal and intrapersonal heterogeneity, respectively, moving from time $t-1$ to $t$. This visual evidence shows that cultural heterogeneity is relatively stable but not invariant over time.

Figure A1: Within Firm Variation in Interpersonal Heterogeneity

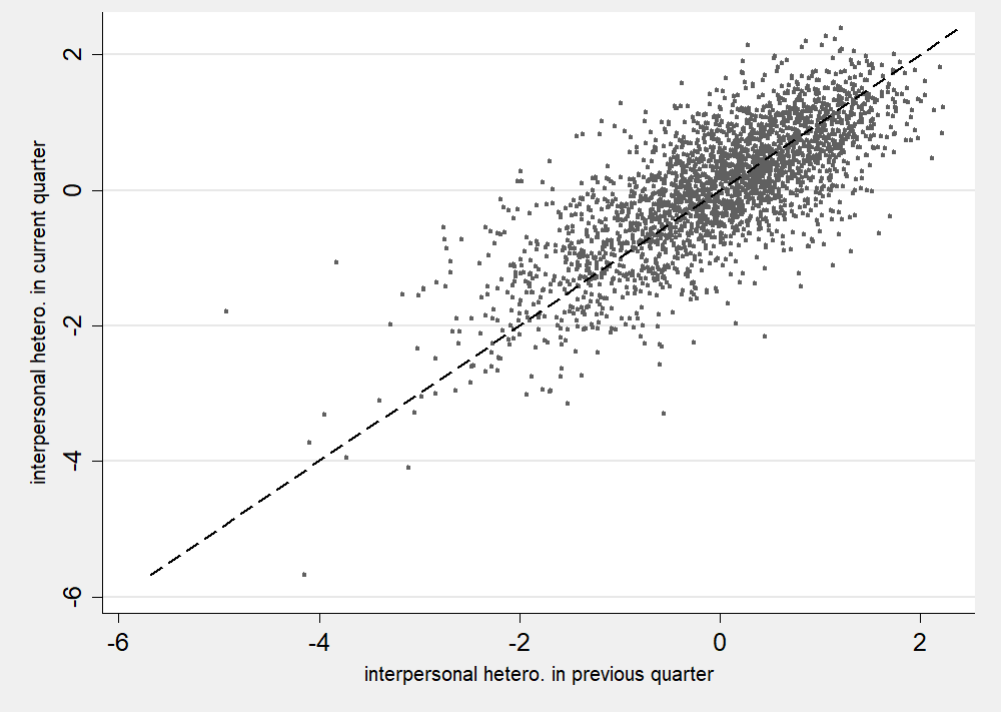


Figure A2: Within Firm Variation in Intrapersonal Heterogeneity

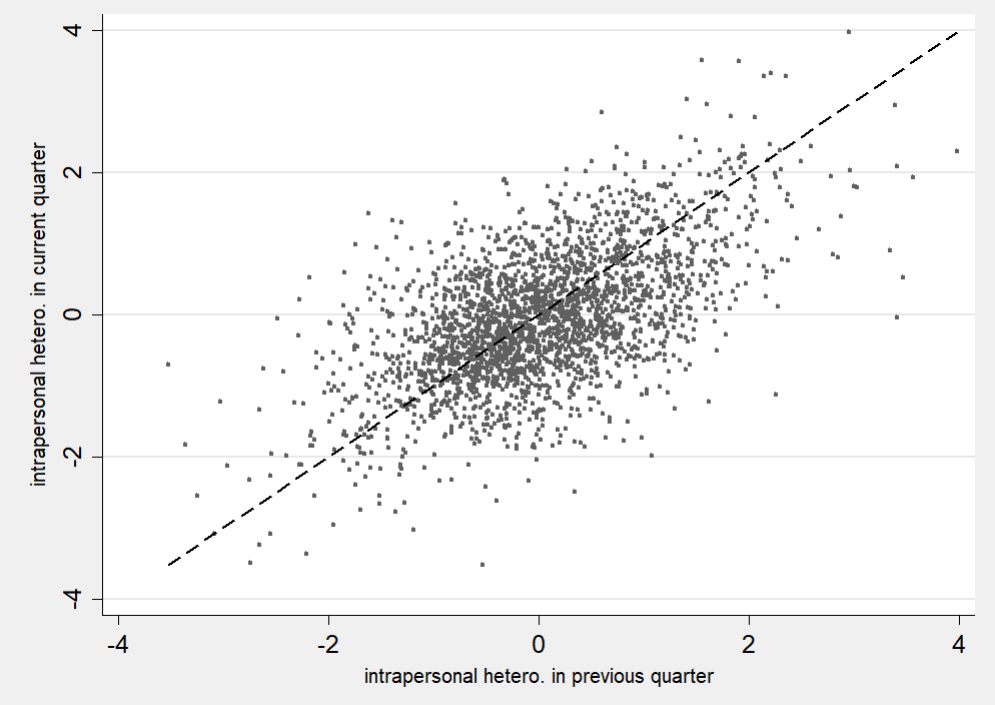

Additionally, we examine the within-firm temporal stability of the cultural heterogeneity measures across the full distributions of the measures. Figures A3 and A4 plot kernel density estimates of the distribution of each culture measure moving within-firm from time $t-1$ to $t$. For both measures, Kolmogorov-Smirnov tests fail to reject the null hypothesis that the two distributions are different, providing statistical evidence that the culture measures exhibit relative stability over time. 
Figure A3: Time Variation in Interpersonal Heterogeneity

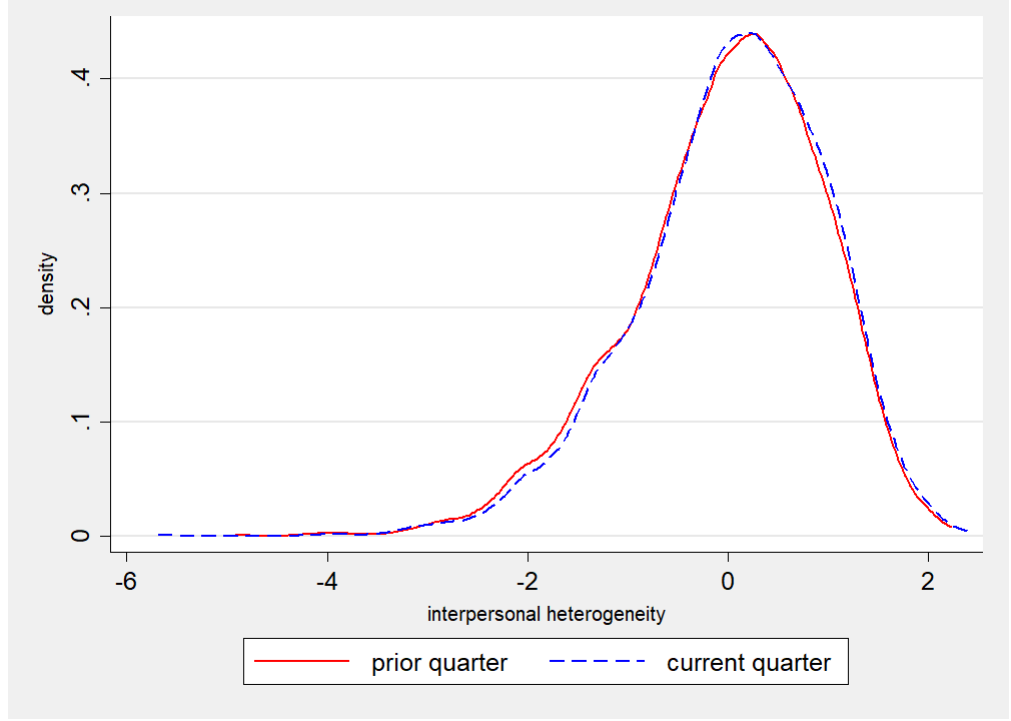

Figure A4: Time Variation in Intrapersonal Heterogeneity

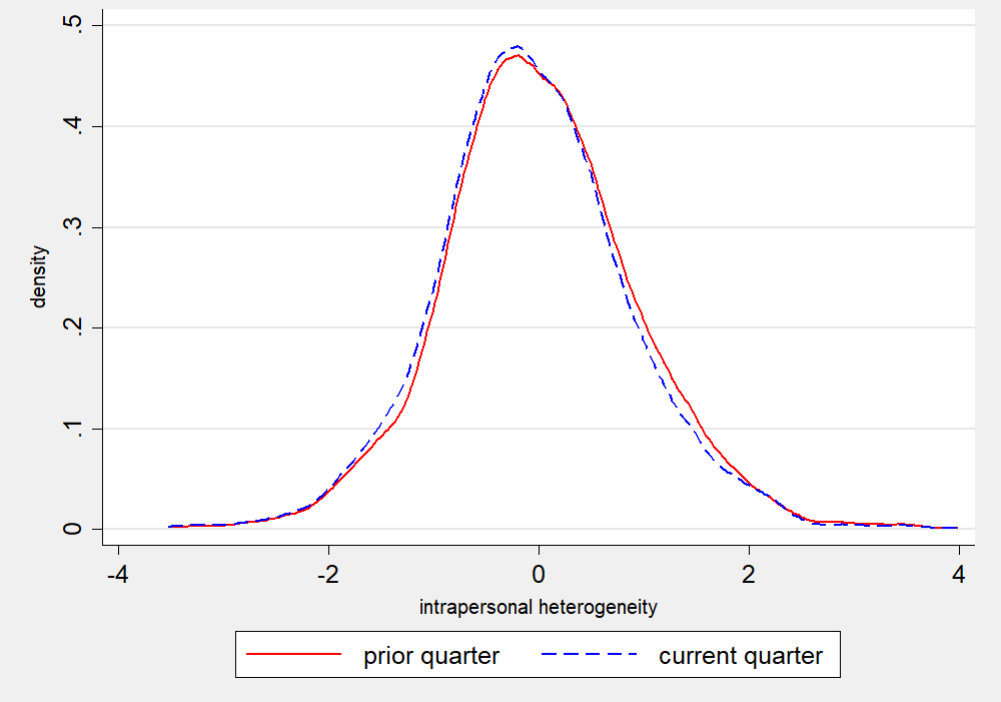

\section{Construct Validity}

Beyond the face validity of the cultural topics that we demonstrated in Table 1, our heterogeneity measures themselves have construct validity as capturing variation along these culture dimensions.

Table A1 shows the firms in the most represented industry in the data that score highest and lowest 
on both cultural heterogeneity measures. Firms are split into large and small firms because the culture measures vary to some degree with firm size. Xerox has high interpersonal heterogeneity, or high disagreement among employees about how to characterize the culture. This accords with lay accounts of Xerox's culture in the study period, during which a newly appointed CEO vowed to redefine the culture. Conversely, Facebook has low interpersonal heterogeneity, or high agreement about the culture. This is consistent with the company's well-known emphasis on maintaining a startup culture focused on innovation, autonomy, and open collaboration. The firms high and low on intrapersonal heterogeneity similarly conform to intuition. For example, MicroStrategy has high intrapersonal heterogeneity, meaning its culture is organized about a broad, diverse set of cultural topics. Instead of keeping its engineers behind desks, the company is known to encourage them to work in the field in collaboration with clients so as to expose them to more challenges and potential solutions.

Table A1: Business Service Firms with Highest/Lowest Cultural Heterogeneity Scores, 2008-2015

\begin{tabular}{lll}
\hline \hline & Large Firms & Small Firms \\
\hline Highest Interpersonal Heterogeneity & Xerox & Kelly Services \\
& SAP & Convergys \\
& Paypal & TeleTech \\
\hline Lowest Interpersonal Heterogeneity & Amdocs & National Instruments \\
& Facebook & Sapient \\
& Wipro & Cornerstone OnDemand \\
\hline \hline Highest Intrapersonal Heterogeneity & Microsoft & MicroStrategy \\
& Harris Corp & National Instruments \\
& Facebook & Intuit \\
\hline Lowest Intrapersonal Heterogeneity & Wipro & Virtusa \\
& Infosys & Syntel \\
& CGI Group & IGATE \\
\hline \hline
\end{tabular}

Notes: Restricted to firms with at least 3 quarterly observations. Large and small firms delimited by industry median size.

Additional face validity is demonstrated in the association between the cultural heterogeneity measures and Glassdoor respondents' subjective assessments of the quality of firm culture and values. Generally speaking, we expect more interpersonally heterogeneous cultures to engender lower approval from members, and more intrapersonally heterogeneous cultures to elicit higher 
approval. In supplementary Coarsened Exact Matching models, interpersonal heterogeneity is associated with a lower average culture and values rating and intrapersonal heterogeneity with a higher rating. 


\section{APPENDIX B: Glassdoor Data Details and Reviewer Robustness}

\section{Checks}

Employees reviewing their company are required to enter both positive ("pro") and negative ("con") comments. Since our objective was to identify the general cultural dimensions mentioned by employees without regard to valence, we combined the pro and con text when analyzing the reviews. Examining the most highly-weighted words for each LDA culture topics reveals that the model identifies cultural topics that are largely agnostic with respect to valence. In other words, both positive and negative review text contribute to most of the culture topics. A close reading of the review text for several firms revealed that pro and con text often characterize the culture the same way, regardless of whether an individual reviewer is mentioning a given topic. We suspect this is because reviewers often key in on either a positive or negative aspect of the same underlying culture.

Most visitors come to Glassdoor first and foremost to search for jobs rather than to post an employer review. Glassdoor employs a "give to get" model to solicit employer reviews from users. In order to receive unlimited access to the site's content, users have to submit an anonymous employer review. Research using the Glassdoor data has found that this method mitigates ratings bias by reducing the prevalence of extremely positive and negative reviews (Marinescu et al., 2018).

Since the employees who write Glassdoor reviews were not selected through random sampling from the population of firm employees, a concern is that systematic variation in the number or composition of reviewers is driving the observed associations between the cultural heterogeneity measures and firm performance. We conducted two checks to examine the robustness of our results to potentially non-random selection of employees into writing Glassdoor reviews: 1) modeling within-firm variation in the number and composition of reviews as a function of firm size and

performance, and 2) modeling within-firm variation in the cultural heterogeneity measures as a function of number and composition of reviews and firm performance and size. The sample includes 
firms with at least six quarterly observations so as to have enough within-firm observations to include firm fixed effects.

Table B1 shows within-firm models of the number and composition of reviews used when calculating the cultural heterogeneity measures. These models test whether the number or composition of reviewers systematically changes during periods of high or low firm performance, which could bias our calculations of cultural heterogeneity. We examined reviewer composition by measuring the percentage of reviews in a given firm/quarter written by employees in managerial positions as opposed to lower-level employees, as indicated by non-missing job title information. Models 1 and 2 show that net of firm size, the number of Glassdoor reviews does not vary as a function of either lagged Return on Assets (ROA) or Tobin's Q (TQ). Specifications 3 and 4 model the percentage of managers writing reviews as function of firm performance while controlling for number of reviews and firm size. Reviewer composition is insensitive to lagged ROA, but the percentage of managers decreases with increasing Tobin's Q. This result prompted us to include the percentage of managers as a control in our multivariate Tobin's Q models - inclusion of the control had virtually no impact on the size or significance of the intrapersonal heterogeneity coefficient. Thus,our findings appear to be robust to (observable) changes in reviewer composition.

Table B2 shows within-firm models of the cultural heterogeneity measures as a function of the number and composition of reviews, as well as firm performance and size. These models directly test whether, net of firm size and lagged performance, the cultural heterogeneity measures vary with the number or composition of reviews. Models 1 and 2 show that both the interpersonal and intrapersonal heterogeneity measures have strong positive associations with the number of reviews, which reflects the sensitivity of the the measures to the number of reviews as inputs. These results prompted us to explicitly match on number of reviews in our coarsened exact matching models so as to ensure that variation in the number of reviews is not driving the results. In contrast, the 
Table B1: Reviewer Characteristics on Performance

\begin{tabular}{lcccc}
\hline \hline & $(1)$ & $(2)$ & $(3)$ & $(4)$ \\
& $\ln (\#$ reviews $)$ & $\ln (\#$ reviews $)$ & $\%$ Managers & $\%$ Managers \\
\hline Lag ROA & -0.0075 & & 0.0000018 & \\
& $(1.54)$ & & $(0.00)$ & \\
Lag TQ & & -0.091 & & $-0.017^{*}$ \\
& & $(1.12)$ & & $(2.38)$ \\
Log of Number of Reviews & & & -0.0029 & -0.0034 \\
& & & $(0.61)$ & $(0.69)$ \\
Lag Log of Assets & & & & -0.011 \\
& $0.19^{*}$ & 0.15 & -0.0031 & $(0.97)$ \\
Constant & $(2.53)$ & $(1.83)$ & $(0.28)$ & \\
& $1.98^{* *}$ & $2.52^{* *}$ & $0.40^{* * *}$ & $0.51^{* * *}$ \\
Year FEs & $(2.73)$ & $(2.86)$ & $(3.59)$ & $(4.37)$ \\
Quarter FEs & yes & yes & yes & yes \\
Firm FEs & yes & yes & yes & yes \\
Firm/Quarters & yes & yes & yes & yes \\
\hline \hline
\end{tabular}

Absolute $t$ statistics in parentheses

Standard errors clustered by firm

${ }^{*} p<0.05,{ }^{* *} p<0.01,{ }^{* * *} p<0.001$

percentage of managers is not significantly associated with the culture measures. 
Table B2: Cultural Heterogeneity on Reviewer Characteristics and Performance

\begin{tabular}{lcc}
\hline \hline & $(1)$ & $(2)$ \\
& & \\
& Interpersonal Hetero. & Intrapersonal Hetero. \\
\hline Log \# Reviews & $(4.55)$ & $-0.23^{* * *}$ \\
& & $(5.20)$ \\
& 0.30 & -0.12 \\
Lag ROA & $(1.13)$ & $(0.33)$ \\
& -0.0023 & 0.0029 \\
Lag TQ & $(0.48)$ & $(0.49)$ \\
& -0.00016 & 0.055 \\
Lag Log Assets & $(0.00)$ & $(0.65)$ \\
& -0.050 & 0.087 \\
Constant & $(0.58)$ & $(0.91)$ \\
& $-2.01^{*}$ & 1.42 \\
& $(2.21)$ & $(1.38)$ \\
\hline Quarter FEs & yes & yes \\
Firm FEs & yes & 2730 \\
Firm/Quarters & 2730 & \\
\hline \hline Absolute $t$ statistics in parentheses \\
Standard errors clustered by firm \\
${ }^{*} p<0.05,{ }^{* *} p<0.01,{ }^{* * *} p<0.001$ & \\
& &
\end{tabular}




\section{APPENDIX C: Interrelationship between the Two Heterogeneity}

\section{Measures}

In the main body of the paper, we examine the independent relationship between the two cultural heterogeneity types - interpersonal and intrapersonal-and organizational performance. We show that the former predicts profitability and the latter is associated with growth potential and innovation. A natural extension would be to explore how the two types of heterogeneity relate to one another in producing these outcomes.

Two considerations give us pause in performing such an analysis, however. First, we expect this relationship to be complex and non-linear. Our theoretical framework leads to hypotheses about the independent main effects of interpersonal and intrapersonal heterogeneity on performance, but it does not straightforwardly imply what their joint effects would be. For example, greater intrapersonal heterogeneity implies a greater potential for interpersonal confusion: individuals who espouse multiple and potentially conflicting cultural frames might appear to their peers as behaviorally inconsistent across situations. At the same time, greater within-person cultural diversity mechanically increases, on average, the likelihood that two individuals would have cultural overlap. In other words, intrapersonal heterogeneity might both lead to greater and to diminished capacity for interpersonal coordination.

Second, although the two concepts are analytically distinct, their operationalization leads to a non-linear mechanical relationship between them. For example, at the extreme positive end of intrapersonal heterogeneity, i.e., when all organizational members equally espouse all possible cultural elements, interpersonal heterogeneity will, by design, be 0 . But when intrapersonal heterogeneity is low, for example, when all members adopt one cultural element each, interpersonal heterogeneity can range from 0 (when all members espouse the same element) to 1 (when each espouses a different element). This relationship becomes even more complex when there exists variability between members' levels of within-person heterogeneity. 
To address the second, mechanical problem, we implement a procedure to adjust interpersonal heterogeneity relative to what would be expected at random, holding intrapersonal heterogeneity constant. Let $N_{o t}$ be the number of individuals reviewing organization $o$ at time $t$. We can represent the set of reviews for organization $o$ at time $t$ as an $N_{o t} \mathrm{x} K$ matrix $X_{o t}$ (where $K$ is the number of LDA topics). Each row represents the probability distribution of each individual review over the set of $K$ topics. To induce the expected interpersonal heterogeneity, we randomly permute each row in $X_{o t}$ to produce a permuted dataset labeled $X_{o t}^{i}$, and calculate interpersonal heterogeneity $B\left(X_{o t}^{i}\right)$, as defined in eq. 3. This procedure preserves intrapersonal heterogeneity as it does not change the shape of the distribution of probabilities over topics within each review. Nevertheless, it affects interpersonal heterogeneity by randomly shifting the topics over which these probability distributions are distributed. We repeat the process $n=1,000$ times to produce a reference distribution of interpersonal heterogeneity. The mean of this reference distribution is the expected interpersonal heterogeneity, $E\left(B_{o t}\right)=\frac{1}{n} \sum_{i=1}^{n} B\left(X_{o t}^{i}\right)$. We define the adjusted interpersonal heterogeneity as the distance between the observed and expected interpersonal heterogeneity, $\tilde{B}_{o t}=B_{o t}-E\left(B_{o t}\right)$.

$\tilde{B}_{o t}$ is the interpersonal heterogeneity that is not mechanically explained by intrapersonal heterogeneity. We find that for all our firm-quarter observations this variable is negative, suggesting, as one would assume, that all firms exhibit a level of interpersonal heterogeneity that is lower than what would be expected at random. In other words, all firms have greater cultural consensus than would be the case if an equally sized set of individuals with random cultural preferences would be assembled, keeping this set of individuals' level of intrapersonal heterogeneity constant. The analyses presented in this appendix use the adjusted measure of interpersonal heterogeneity whenever the two heterogeneity variables are included in the same model.

We begin by revisiting the CEM models that test our two hypotheses while including both heterogeneity variables in the models. Model 1 in Table $\mathrm{C} 1$ tests Hypothesis 1 and reproduces Model 2 in Table 4. As expected, and consistent with Hypothesis 1, (adjusted) interpersonal heterogeneity remains negatively predictive of ROA, but intrapersonal heterogeneity does not. Models 2 to 4 in 
Table C1 revisit Hypothesis 2, corresponding to Models 2, 5 \& 7 in Table 5. Consistent with Hypothesis 2, intrapersonal heterogeneity is predictive of greater market valuation and innovation output, but interpersonal heterogeneity is not. The only exception is Model 3, which is marginally significant (at $p=0.06$ ). In other model specifications (e.g., in an OLS model with quarter and industry fixed effects, corresponding to Model 3 in Table 5) we find that intrapersonal heterogeneity is significantly predictive of the number of patents (at $p<0.01)$ but that interpersonal heterogeneity is not.

Overall, the results in Table $\mathrm{C} 1$ indicate that our findings are robust to the inclusion of both heterogeneity variables in our models and that the two different types of heterogeneity are differentially predictive of performance as we hypothesize. Non-hypothesized relationships between cultural heterogeneity and performance are not driving our results (in additional analyses that we do not report here we find that, when modeled separately in a CEM specification, intrapersonal heterogeneity does not predict profitability and interpersonal heterogeneity does not predict market valuation or innovation).

Although theoretical predictions about an interaction effect between interpersonal and intrapersonal heterogeneity are not straightforward, we cautiously explore them in Table C2. Our main hypotheses focus on the coordination disadvantages of interpersonal heterogeneity and the creative advantages of intrapersonal heterogeneity. Yet our outcomes are not perfect measures of coordination or creativity. For example, we use ROA as an indication of coordination efficiencies, but we expect that profitability is also affected, to some extent, by creativity. Similarly, patenting output depends on creativity, but the ability to translate creative ideas into useful innovation also depends on team coordination capabilities. We therefore expect that organizations that simultaneously exhibit low levels of interpersonal heterogeneity and high levels of intrapersonal heterogeneity — that is, firms with consensual and broad cultures - will also exhibit high profitability and innovation relative to other firms. Conversely, we expect that organizations with high levels of interpersonal heterogeneity and low levels of intrapersonal heterogeneity - that is, firms in which individuals 
espouse different and narrow cultural beliefs - will exhibit lower performance on both dimensions.

To evaluate this proposition, we explore interactions between the two measures in Table C2. Due to expected nonlinearities in effects, we dichotomize the interpersonal and intrapersonal heterogeneity variables into high and low binary variables at their respective medians and examine their interaction, which produces four different quadrants. This exercise leads to a significant reduction in statistical power. We therefore only explore OLS models without coarsened exact matching of observations and include only one quadrant dummy in each model. The results reported in Table C2 are broadly consistent with our assumption about the interaction between the two types of cultural heterogeneity. Firms with low interpersonal and high intrapersonal heterogeneity exhibit greater profitability, higher Tobin's Q and higher innovation output than other firms. Culturally fragmented organizations, in contrast, whose employees adopt different and narrow cultural beliefs, exhibit low profitability and market valuation. These firms also exhibit lower levels of innovation, but at marginally statistically significant levels. Additional analyses wherein we include multiple quadrant dummies in each model do not yield consistent and statistically significant results. We therefore interpret the results in Table $\mathrm{C} 2$ as suggestive but inconclusive evidence for the non-linear, joint effects of interpersonal and intrapersonal heterogeneity on performance. We leave to future work further theoretical development and empirical exploration of the interrelationships between the two cultural heterogeneity measures. 
Table C1: CEM Models with Adjusted Interpersonal Heterogeneity Measure

\begin{tabular}{|c|c|c|c|c|}
\hline & $\begin{array}{c}(1) \\
\text { ROA } \\
\text { Matched }\end{array}$ & $\begin{array}{c}(2) \\
\text { TQ } \\
\text { Matched }\end{array}$ & $\begin{array}{c}(3) \\
\text { Log Patent Count } \\
\text { Matched }\end{array}$ & $\begin{array}{c}(4) \\
\text { \# Back. Cites } \\
\text { Matched }\end{array}$ \\
\hline Lag Intrapersonal Hetero. & $\begin{array}{c}0.026 \\
(0.21)\end{array}$ & $\begin{array}{c}0.098^{*} \\
(2.10)\end{array}$ & $\begin{array}{c}0.085 \\
(1.88)\end{array}$ & $\begin{array}{l}0.25^{*} \\
(2.46)\end{array}$ \\
\hline Lag Interpersonal Hetero. (adj.) & $\begin{array}{l}-41.8^{*} \\
(2.12)\end{array}$ & $\begin{array}{c}12.5 \\
(1.33)\end{array}$ & $\begin{array}{c}8.86 \\
(1.51)\end{array}$ & $\begin{array}{c}8.82 \\
(0.67)\end{array}$ \\
\hline Constant & $\begin{array}{c}-0.73 \\
(1.52)\end{array}$ & $\begin{array}{c}1.31^{* * *} \\
(5.30)\end{array}$ & $\begin{array}{c}0.21 \\
(1.38)\end{array}$ & $\begin{array}{c}1.21 \\
(1.67)\end{array}$ \\
\hline Matching Weights & yes & yes & yes & yes \\
\hline Stratum FEs & yes & yes & yes & yes \\
\hline Firm/Quarters & 794 & 699 & 714 & 355 \\
\hline
\end{tabular}

Table C2: Performance and Patent Outcomes on Heterogeneity Quadrants

\begin{tabular}{|c|c|c|c|c|c|c|c|c|}
\hline & $\begin{array}{c}(1) \\
\text { ROA }\end{array}$ & $\begin{array}{c}(2) \\
\text { ROA }\end{array}$ & $\begin{array}{l}\text { (3) } \\
\text { TQ }\end{array}$ & $\begin{array}{l}\text { (4) } \\
\text { TQ }\end{array}$ & $\begin{array}{c}(5) \\
\text { Log \# Pats. }\end{array}$ & $\begin{array}{c}\text { (6) } \\
\text { Log \# Pats. }\end{array}$ & $\begin{array}{c}\text { (7) } \\
\text { \# Back. Cites }\end{array}$ & $\begin{array}{c}(8) \\
\text { \# Back. Cites }\end{array}$ \\
\hline High Inter., Low Intra. & $\begin{array}{c}-0.62^{* * *} \\
(4.01)\end{array}$ & & $\begin{array}{c}-0.23^{* * *} \\
(5.18)\end{array}$ & & $\begin{array}{c}-0.14 \\
(1.87)\end{array}$ & & $\begin{array}{c}-0.16 \\
(1.92)\end{array}$ & \\
\hline Low Inter., High Intra. & & $\begin{array}{l}0.43^{* *} \\
(3.06)\end{array}$ & & $\begin{array}{c}0.16^{* * *} \\
(3.45)\end{array}$ & & $\begin{array}{c}0.17^{*} \\
(2.30)\end{array}$ & & $\begin{array}{c}0.28^{* * *} \\
(3.54)\end{array}$ \\
\hline Lag Log Assets & $\begin{array}{c}0.14 \\
(1.16)\end{array}$ & $\begin{array}{l}0.099 \\
(0.84)\end{array}$ & $\begin{array}{c}-0.083^{*} \\
(2.08)\end{array}$ & $\begin{array}{c}-0.097^{*} \\
(2.38)\end{array}$ & $\begin{array}{l}0.21^{* *} \\
(2.72)\end{array}$ & $\begin{array}{l}0.21^{* *} \\
(2.67)\end{array}$ & $\begin{array}{l}0.15^{*} \\
(2.29)\end{array}$ & $\begin{array}{l}0.14^{*} \\
(2.37)\end{array}$ \\
\hline Lag Log \# Reviews & $\begin{array}{l}0.40^{* *} \\
(2.74)\end{array}$ & $\begin{array}{l}0.42^{* *} \\
(2.72)\end{array}$ & $\begin{array}{l}0.18^{* *} \\
(3.21)\end{array}$ & $\begin{array}{c}0.18^{* *} \\
(3.19)\end{array}$ & $\begin{array}{l}0.036 \\
(0.37)\end{array}$ & $\begin{array}{l}0.040 \\
(0.40)\end{array}$ & $\begin{array}{l}-0.19^{*} \\
(2.30)\end{array}$ & $\begin{array}{l}-0.18^{*} \\
(2.27)\end{array}$ \\
\hline Constant & $\begin{array}{c}-0.19 \\
(0.20)\end{array}$ & $\begin{array}{l}-0.52 \\
(0.52)\end{array}$ & $\begin{array}{c}2.80^{* * *} \\
(8.33)\end{array}$ & $\begin{array}{c}2.69^{* * *} \\
(7.84)\end{array}$ & $\begin{array}{l}-0.56 \\
(0.76) \\
\end{array}$ & $\begin{array}{c}-0.77 \\
(0.99) \\
\end{array}$ & $\begin{array}{c}2.40^{* * *} \\
(4.65)\end{array}$ & $\begin{array}{c}2.13^{* * *} \\
(4.32)\end{array}$ \\
\hline Quarter FEs & yes & yes & yes & yes & yes & yes & yes & yes \\
\hline Industry FEs & yes & yes & yes & yes & yes & yes & yes & yes \\
\hline Firm/Quarters & 2616 & 2616 & 2595 & 2595 & 3296 & 3296 & 949 & 949 \\
\hline
\end{tabular}

